\title{
Microbial production of short chain diols
}

\author{
Yudong Jiang ${ }^{1,2}$, Wei Liu ${ }^{1 *}$, Huibin Zou' ${ }^{1}$, Tao Cheng ${ }^{1}$, Ning $\operatorname{Tian}^{1}$ and Mo Xian ${ }^{1 *}$
}

\begin{abstract}
Short chain diols (propanediols, butanediols, pentanediols) have been widely used in bulk and fine chemical industries as fuels, solvents, polymer monomers and pharmaceutical precursors. The chemical production of short chain diols from fossil resources has been developed and optimized for decades. Consideration of the exhausting fossil resources and the increasing environment issues, the bio-based process to produce short chain diols is attracting interests. Currently, a variety of biotechnologies have been developed for the microbial production of the short chain diols from renewable feed-stocks. In order to efficiently produce bio-diols, the techniques like metabolically engineering the production strains, optimization of the fermentation processes, and integration of a reasonable downstream recovery processes have been thoroughly investigated. In this review, we summarized the recent development in the whole process of bio-diols production including substrate, microorganism, metabolic pathway, fermentation process and downstream process.
\end{abstract}

Keywords: Propanediol, Butanediol, Microbial synthesis, Downstream technologies

\section{Introduction}

Platform chemicals are the ones that serve as the basic starting materials for producing chemical intermediates, building block compounds, and polymers. Giving an example, ethylene is used as a building block compound for the production of polyethylene. Short chain diols, which are exemplified by ethylene glycol, propanediols (PDO), butanediols (BDO), are of great importance in the family of platform chemicals. Owing to their unique structures and reaction activities, they are widely used for the synthesis of polymers, special chemicals and chemical intermediates.

The chemical production of short chain diols from petroleum materials has been developed and optimized for decades [1]. For example, Reppe chemistry used acetylene for BDO production representing the largest portion of this field [2]. However, the chemical syntheses methods of diols usually require high pressure, high temperature, expensive catalyzers, release of toxic intermediates, dependence on non-renewable materials, which result in complex process and low yield [3]. The development of environmentally benign, or "green", processes for the production of chemicals is of increasing

\footnotetext{
*Correspondence: liuwei@qibebt.ac.cn; xianmo@qibebt.ac.cn

${ }^{1}$ CAS Key Laboratory of Bio-based Materials, Qingdao Institute of Bioenergy and Bioprocess Technology, Chinese Academy of Sciences, No. 189 Songling Road, Qingdao 266101, China

Full list of author information is available at the end of the article
}

importance as nonrenewable resources are depleted and world population grows. Microbial fermentation processes are particularly attractive in this regard because they typically use renewable feedstocks such as glucose or sucrose and do not generate toxic byproducts.

Currently, a variety of biotechnologies have been developed for the microbial production of short chain diols. Previous articles have individually or partially reviewed the biotechnological production of 1,3-PDO, 1,2-PDO, 1,4-BDO or 2,3-BDO [4-7]. In this review, the whole processes of bio-diols production were summarized and discussed, from upstream process including substrate, microorganism, metabolic pathway and fermentation process, to downstream process. Furthermore, the research progress and potential biosynthesis method of pentanediols were discussed in this paper.

\section{Substrate}

For the microbial production of diols the substrate cost can make up much of the whole producing cost. Glucose is widely used in fermentation processes. DuPont and Genencor Inc. have successfully developed the engineered E. coli to produce 1,3-PDO from glucose which represents the state-of-the art [8]. The price of glucose is a little expensive for large-scale commercial production. Glycerol is an inevitable byproduct generated during both bioethanol and biodiesel production processes, and the tremendous 
growth of these industries has led to a dramatic decrease in crude glycerol prices over the past few years [9-11]. Studies showed that raw glycerol can be used for diol production. Crude glycerol was converted to 1,3-PDO by a newly isolated Citrobacter freundii strain FMCC-B 294 (VK-19) with a relatively high conversion yield of $0.36 \mathrm{~g} / \mathrm{g}$ [12]. A mutant strain of Clostridium pasteurianum appeared great tolerant to crude glycerol and in a fermentation, the productivity of 1,3-PDO was $1 \mathrm{~g} / \mathrm{l} / \mathrm{h}$ with a yield of $0.21 \mathrm{~g} / \mathrm{g}$ [13]. An engineered $E$. coli strain produced S-1,2-PDO aerobically from crude glycerol with a titer of $0.44 \mathrm{~g} / \mathrm{L}$ [14]. Production of 2,3-BDO was achieved using crude glycerol by an engineered E. coli [15].

For further reduce the cost, some more cheaper and abundant substrates, which include renewable agricultural resources (starch), food industry residues (starch hydrolysate, molasses and whey permeate) and lignocellulosic biomass (wood hydrolysate) have a distinguished edge. Several studies on 2,3-BDO production from lignocellulosic biomass hydrolysates, such as straw paper pulp enzymatic hydrolysate and corncob acid hydrolysate, were reported in recent years [16-18]. For example, cellodextrin was used to produce 2,3-BDO with an engineered $E$. coli. At an approximately $24 \mathrm{~h}$ fermentation, the highest yield of BDO was $0.84 \mathrm{~g} / \mathrm{g}$ [19].

Jerusalem artichoke is an inexpensive and readily available non-grain raw material. Fresh Jerusalem artichoke tubers contain nearly $20 \%(\mathrm{w} / \mathrm{w})$ carbohydrates, in which there is $70-90 \%(w / w)$ inulin [20,21]. Some strains of Paenibacillus polymyxa were proved to be capable of fermenting biopolymers such as inulin without previous hydrolysis [22]. For example, $37 \mathrm{~g} / \mathrm{L}$ of $(\mathrm{R}, \mathrm{R})-2,3-\mathrm{BDO}$ at more than $98 \%$ optical purity was achieved by a $P$. polymyxa ZJ-9 with a medium for one-step fermentation of raw inulin extract from Jerusalem artichoke tubers [23]. This process greatly decreased the raw material cost and thus facilitated its practical application. In a previous research, 2,3-BDO production from Jerusalem artichoke by Bacillus polymyxa ATCC 12321 was optimized in batch culture [24]. Additionally, Jerusalem artichoke tubers was also utilized for 2,3-BDO production by Klebsiella pneumoniae [25].

Besides above mentioned substrates, $\mathrm{CO}_{2}$ is used to synthesize 1,2-PDO. A latest study reported the photosynthetic production of 1,2-PDO from $\mathrm{CO}_{2}$ using a genetically engineered cyanobacterium Synechococcus elongatus PCC 7942. The synthetic pathway is shown in Figure 1. The best engineered S. elongatus strain LH22 introducing $m g s A$ and $y q h D$ both from E. coli and the adh from Clostridium beijerinckii produced $\sim 150 \mathrm{mg} / \mathrm{L} \mathrm{1,2-PDO} \mathrm{[26].}$ Direct 1,2-PDO production from $\mathrm{CO}_{2}$ in photosynthetic organisms recycles the atmospheric $\mathrm{CO}_{2}$ and will not compete with food crops for arable land, compared to the previously reported biological production processes using sugar or glycerol as the substrates. Even though this

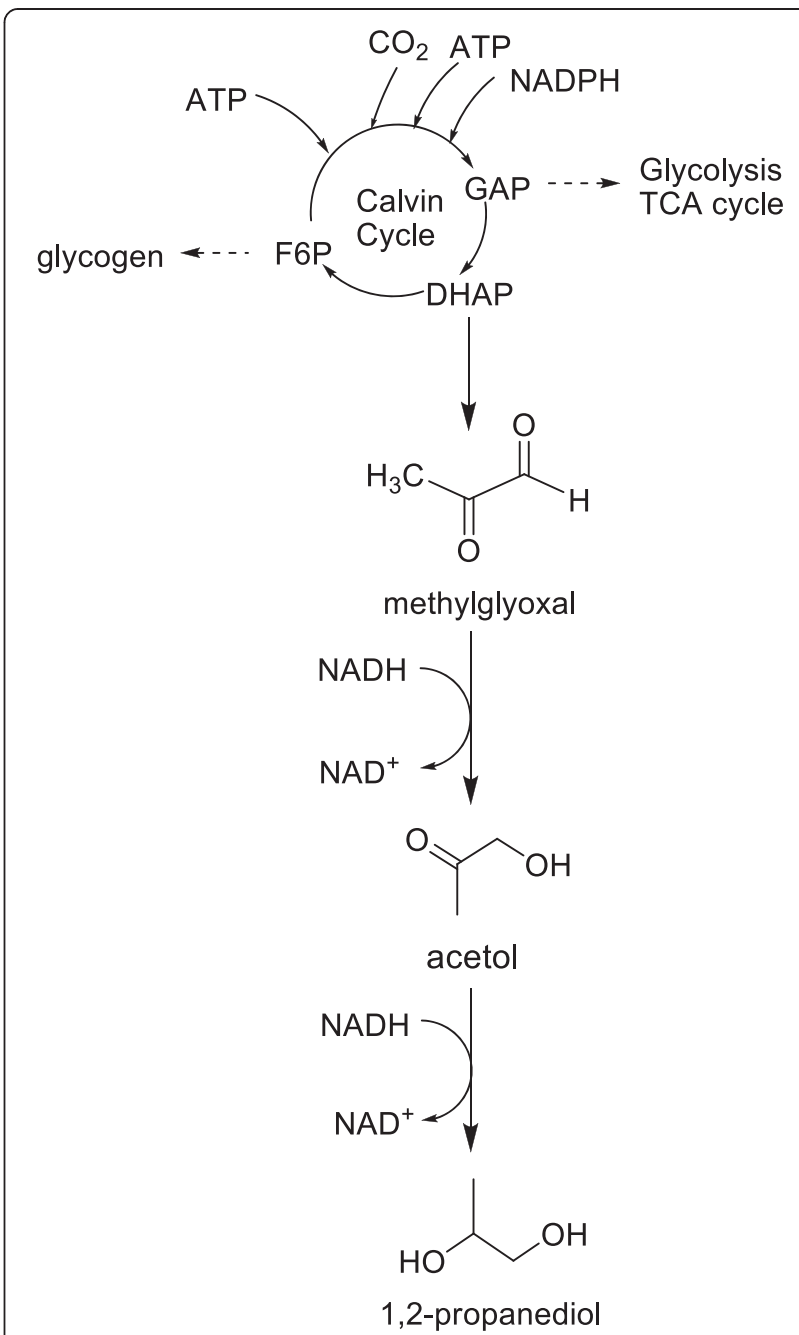

Figure 1 Utilization of $\mathrm{CO}_{2}$ for 1,4-BDO production. GAP: glyceraldehyde-3-phosphate; F6P: fructose-6-phosphate; DHAP: dihydroxyacetone phosphate.

method has advantages like environmentally friendly and low cost, it is essential to further improve yield and productivity increasing the competitiveness.

\section{Microorganism: wide and engineered strains 1,3-PDO}

A number of microorganism species are able to accumulate short chain diols. 1,3-PDO can be produced by wide type strains like Citrobacter sp., Clostridium sp. and Klebsiella sp.. Citrobacter freundii strain FMCC-B 294 (VK-19) was revealed to convert crude glycerol to 1,3-PDO [12,27]. It has the ability to tolerate highly elevated amount of crude glycerol and $68.1 \mathrm{~g} / \mathrm{L}$ of PDO were produced under fed-batch fermentation [27]. Citrobacter amalonaticus Y19 was investigated about 1,3-PDO production, and final yield reached $0.20 \mathrm{~g} / \mathrm{g}$ under anaerobic conditions using fumatate and $\mathrm{CoCl}_{2}$ as electron acceptors [28]. The 1,3-PDO production potential of Clostridium saccharobutylicum 
NRRL B-643 was revealed in a previous study [29]. This strain was able to consume feed glycerol almost entirely, which made it to be a promising type for further 1,3-PDO studies. A mutant strain of Clostridium pasteurianum was obtained by random mutagenesis mediated using ethane methyl sulfonate to tolerate high concentrations of crude glycerol [13]. Klebsiella pneumoniae is a suitable biocatalyst for the production of 1,3-PDO, but limited by poor growth characteristics and higher pathogenic. A new Klebsiella pneumoniae J2B was isolated to produce 1,3-PDO, which showed better growth properties, lower lipopolysaccharide production, better ability to cope with the inhibitory effects of toxic reductive metabolites, and a higher sedimentation rate [30].

However, some efficient microbial producers like Klebsiella sp. are classified as class 2 (or pathogenic), thus not suitable for large scale industrial applications. The native 1,3-PDO producers from the lactobacilli group generally recognized as safe are potential biocatalysts for 1,3-PDO production. Lactobacillus reuteri, Lactobacillus brevis and Lactobacillus bucheneri have been reported to produce 1,3-PDO from mixtures of glucose and glycerol [31,32]. Recently, Lactobacillus diolivorans was reported to reach product concentrations up to $86 \mathrm{~g} / \mathrm{L}$ coupled with the addition of Vitamin $B_{12}$ to the culture medium [33]. The max yield was $0.71 \mathrm{~g} / \mathrm{g}$ when using $0.05 \mathrm{~mol}$ glucose $/$ mol glycerol without acetic acid in the batch medium. Another native producer, Lactobacillus panis strain (designated as PM1), was isolated from a stored bioethanol thin stillage sample [34]. It is a promising producer for industrial application with the high tolerance for salts and organic acids, and a wider tolerance for $\mathrm{pH}$ settings. Recent development in engineering of 1,3-PDO production strains are not covered in details in this paper, which are referred to representative reviewer [7].

\section{1,2-PDO}

1,2-PDO can be produced by some natural producers like Thermoanaerobacterium thermosaccharolyticum [35], Clostridium thermosaccharolyticum [36] and Clostridium sphenoides [37]. Thermoanaerobacterium thermosaccharolyticum, has some properties such as being able to ferment a variety of renewable sugars and being thermophilic so that it can be seen as a potential host. Though 1,2-PDO production have been achieved using $T$. thermosaccharolyticum, the 1,2-PDO synthesis of this bacterium is not well understood. While Corynebacterium glutamicum has high potential as a commodity chemicals producer coupled with the prevailing abundant knowledge of its metabolism, this could imply the possibility of a very favorable host for 1,2-PDO production. Overexpressing $m g s$ and cgR_2242, one of the genes annotated as aldo-keto reductases (AKRs) in C. glutamicum, enhanced the 1,2-PDO production to 25
mM compared with the $93 \mu \mathrm{M}$ of wild-type strain after $132 \mathrm{~h}$ incubation under aerobic conditions [38].

Constructing benign $E$. coli catalysts for the production of PDO could be beneficial to commercial production because E. coli is well studied in metabolic mechanism, low cost and easy to culture. An enantiomerically pure R-1,2PDO was produced from glucose in an engineered $E$. coli and $0.7 \mathrm{~g} / \mathrm{L}$ 1,2-PDO was obtained by co-expressing methylglyoxal synthase and glycerol dehydrogenase [39]. A further improvement of 1,2-PDO production in E. coli was conducted through eliminating production of a byproduct, lactate, constructing a complete pathway to 1,2-PDO from DHAP and investigating bioprocessing improvements of a fed-batch fermentation. Finally, a titer of $5 \mathrm{~g} / \mathrm{L}$ of $(R)-1,2-$ PDO was produced, with a final yield of $0.19 \mathrm{~g}$ of $1,2-\mathrm{PDO}$ per gram of glucose consumed [40]. An engineered E. coli strain was reported to produce $5.6 \mathrm{~g} / \mathrm{L}$ 1,2-PDO from glycerol at a yield of $0.21 \mathrm{~g} / \mathrm{g}$ [41]. The advantage of this strain is that the titer and yield achieved were favorable to those obtained with the use of E. coli for the 1,2-PDO production from common sugars.

Saccharomyces cerevisiae is also a widely used genetic engineering bacteria. Saccaromyces cerevisiae strains have been used as 1,2-PDO producer for its higher stability than that of prokaryotes [42-44]. An engineered S. cerevisiae harboring the mgs gene of E. coli-K12 MG1655 and the dhaD gene of Citrobacter freundii achieved $0.45 \mathrm{~g} / \mathrm{L}$ 1,2-PDO in a batch fermentation [42]. The distinguished advantage of this strain was the increased extracellular concentration yield of 1,2-PDO because the external discharge capacity of a cell membrane and the processes of releasing bio-metabolites from a cell membrane determined the economic and utility values of bio-metabolites. Another engineered $S$. cerevisiae strain was constructed by expressing the $E$. coli $m g s$ and gldA genes, which encode methylglyoxal synthase and glycerol dehydrogenase, respectively [44]. This study evaluated the effect of $m g s$ and gldA gene number on 1,2-PDO production showing that the strain containing 3 copies produced the highest level of 1,2-PDO. An recombinant S. cerevisiae was constructed by engineering both glycerol dissimilation and 1,2-PDO pathways. With these strategies, glycerol utilization and grow rate were increased [45]. This is of great importance because the poor growth rate and glycerol utilization ability of wide strain made it difficult to use glycerol as carbon source.

\section{2,3-BDO}

Species noted for its 2,3-BDO producing ability belong to the genera Klebsiella, Enterobacter, Bacillus and Serratia. Native producers, such as Klebsiella pneumoniae [46], Klebsiella oxytoca [47] and Bacillus polymyxa [48], have been used for BDO production. However, the pathogenicity of opportunistic infection caused by the Klebsiella 
species is generally thought to be an obstacle hindering the large-scale 2,3-BDO production. Bacillus and Paenibacillus polymyxa has been reported to produce R,R-2,3-BDO $[24,49,50]$. A newly developed thermophilic Bacillus licheniformis was reported to convert glucose and xylose to D-(-)-2,3-BDO at $50^{\circ} \mathrm{C}$ with the optical purity more than 98\% [51]. As a high temperature producer matching the simultaneous saccharification and fermentation conditions, it has potential to further lower BDO producing cost with low cost lignocellulosic biomass. Enterobacter cloacae NRRL B-23289, isolated from local decaying wood/corn soil samples, demonstrated a 2,3-BDO yield of $0.4 \mathrm{~g} / \mathrm{g}$ arabinose with a corresponding productivity of $0.63 \mathrm{~g} / \mathrm{l} / \mathrm{h}$. The bacterium has the capability to convert multiple mixed sugar substrates to 2,3-BDO thus it may be appropriate for developing the commercial production of 2,3-BDO from corn fiber and other agricultural residues [52].

Strain improvement for efficient microbial 2,3-BDO production involves not only native producers, i.e. homologous hosts, but also microorganisms with acquired ability to form 2,3-BDO via genetic manipulations, i.e. heterologous hosts. The lactic acid bacteria (LAB) are potential alternatives to produce 2,3-BDO with its safety and possession of a natural 2,3-BDO biosynthetic pathway [53]. An engineered Laclobacillus plantarum was constructed through elimination of lactate dehydrogenase activity and expression of butanediol dehydrogenase activity, and $0.49 \mathrm{~g} / \mathrm{g}$ of 2,3-BDO yield was claimed in this engineered strain [54]. Serratia marcescens H30 was reported as a potential strain to produce 2,3-BDO from sucrose [55]. However, Serratia marcescens produces serrawettin W1, a surface-active exolipid, which will result in a lot foam formation leading to microbial contamination and bacterial activity decrease during the 2,3-BDO fermentation process. In order to overcome this drawback, mutants deficient in serrawettin W1 formation were constructed through insertional inactivation of the swrW gene coding for serrawettin W1 synthase [56]. The mutant strain afforded a maximum 2,3-BDO concentration of $152 \mathrm{~g} / \mathrm{L}$ with a productivity of $3 \mathrm{~g} / \mathrm{l} / \mathrm{h}$ and yield of $0.93 \mathrm{~g} / \mathrm{g}$ during a fed-batch culturing.

$E$. coli is frequently used as a heterologous host engineered for enantio-pure 2,3-BDO production. In a report, meso-2,3-BDO was produced by an engineered $E$. coli introduced two biosynthesis genes - budA, encoding acetolactate decarboxylase, and meso-budC, encoding meso-secondary alcohol dehydrogenase from Klebsiella pneumonia [15]. Optically pure meso-2,3-BDO (purity $>99 \%$ ) was produced at high yield of $0.31 \mathrm{~g} / \mathrm{g}$ and $0.21 \mathrm{~g} / \mathrm{g}$ from glucose and crude glycerol feed, respectively, under optimized conditions. There is also another engineered $E$. coli capable of producing meso-2,3-BDO from cellodextrin with a yield of $0.84 \mathrm{~g} / \mathrm{g}$ [19]. The strain was constructed by (i) deleting gene including poxB and ackA-pta, (ii) introducing a synthetic operon which consists of genes encoding acetoacetate synthase, acetoacetate decarboxylase and secondary alcohol dehydrogenase, (iii) periplasmic expressing a Saccharophagus cellodextrinase. E. coli was used to produce acetoin, a precursor of 2,3-BDO [57]. The research could make a guidance for 2,3-BDO industrial biosynthesis.

\section{1,4-BDO}

Though there are not a large amount of reports about 1,4BDO microbial production, now, through the system-wide metabolic engineering, rational protein engineering and genetic engineering strategies, an engineered $E$. coli was capable to directly produce $18 \mathrm{~g} / \mathrm{L}$ 1,4-BDO from renewable carbohydrate feedstock [58]. In addition, the toxicity of 1,4-BDO is reckoned as a key factor restricting its industrial production. So 1,4-BDO tolerant strains are under research. A biosensor, which detected 1,4-BDO using a fluorescent gene under the control of the $y$ hjX (a predicted major facilitator superfamily protein) promoter, was developed on the foundation of the large differential expression of $y h j X$ in response to $1,4-\mathrm{BDO}$, which provided a powerful tool to research the 1,4-BDO production strains [59].

\section{Other short chain diols}

Various microorganisms used for diols production are summarized in Tables 1 and 2 . There are less reported researches on other butanediols except 2,3-BDO, especially 1,3-BDO and 1,2-BDO. But 1,3-BDO is expensive than 2,3-BDO (Table 3), exploring its biosynthesis technology will have broad market value. Some metabolic intermediates of glycolysis and TCA cycle are used in existing biosynthetic pathways of 2,3-BDO and 1,4-BDO, however, there aren't precursors or structural analogs for 1,3-BDO and $1,2-\mathrm{BDO}$ in the major metabolic pathways, therefor this defect restricts their microbial production. Up to mow, the microbial productions of 1,3-BDO have been reported in patents by engineered microbial organisms [60,61]. Alanine, acetoacetyl-CoA and 4-hydroxybutyrylCoA were used as substrates through non-natural metabolic pathways. Though microbial production of 1,2-BDO isn't reported, the existing BDO non-natural microbial production methods provide guidance for its development.

There are rarely reports on the microbial productions of diols which have carbon chain above C4. And just 2,4-pentanediol, which plays an important role as chiral synthons for naturally occurring bioactive substances in the industrial field, has a synthesis report using a biocatalyst. A previous communication revealed the production of (2R,4R)-2,4-pentanediol with Candida boidinii RAMIREZ KK912 by the enantio-selective reduction of 
Table 1 Wide strains for diols production

\begin{tabular}{|c|c|c|c|c|}
\hline Strains & Substrate & Methods & Productivity/Yield & Reference \\
\hline \multicolumn{5}{|l|}{ 1,3-Propanediol } \\
\hline Lactobacillus reuteriATCC 23272 & Glucose and glycerol & Co-fermentation & $1 \mathrm{~g} / \mathrm{l} / \mathrm{h}$ & {$[62]$} \\
\hline Lactobacillus panis PM1 & Glycerol or/and Glucose & - & - & {$[34]$} \\
\hline Klebsiella pneumoniae J2B & Glycerol & Fed-batch fermentation & $0.15 \mathrm{~g} / / / \mathrm{h}$ & {$[30]$} \\
\hline Klebsiella pneumoniae CGMCC 2028 & Glycerol & Continuous fermentation & $0.43 \mathrm{~g} / \mathrm{g}$ & [63] \\
\hline Citrobacter freundii DSM 15979 & Crude glycerol & $\begin{array}{l}\text { Packed bed biofilm reactors operating } \\
\text { under continuous conditions }\end{array}$ & - & [64] \\
\hline Pantoeaagglomerans DSM 30077 & & $\begin{array}{l}\text { Packed bed biofilm reactors operating } \\
\text { under continuous conditions }\end{array}$ & $4 \mathrm{~g} / / / \mathrm{h}$ PUF ${ }^{*}$ & [64] \\
\hline Citrobacteramalonaticus Y19 & Glycerol & $\begin{array}{l}\text { anaerobic conditions using fumatate } \\
\text { and } \mathrm{CoCl}_{2} \text { as electron acceptors }\end{array}$ & $0.20 \mathrm{~g} / \mathrm{g}$ & {$[28]$} \\
\hline $\begin{array}{l}\text { Citrobacterfreundii } \\
\text { FMCC-B 294(VK-19) }\end{array}$ & waste glycerol & Fed-batch fermentation & $0.79 \mathrm{~g} / \mathrm{l} / \mathrm{h}$ & [27] \\
\hline Clostridium butyricum VPI 3266 & Glycerol & Continuous cultures & - & {$[65]$} \\
\hline \multirow[t]{2}{*}{ Clostridium butyricum VPI 1718} & \multirow[t]{2}{*}{ Glycerol } & \multirow[t]{2}{*}{ Batch and continuous cultures } & $0.56 \mathrm{~g} / \mathrm{g}$ (batch culture) & \multirow[t]{2}{*}[66]{} \\
\hline & & & $0.57 \mathrm{~g} / \mathrm{g}$ (continuous culture) & \\
\hline Clostridium butyricum F2b & Industrial glycerol & Batch and continuous cultures & $6 \mathrm{~g} / \mathrm{l} / \mathrm{h}(\max )$ & [67] \\
\hline $\begin{array}{l}\text { Clostridium saccharobutylicum } \\
\text { NRRL B-643 }\end{array}$ & Glycerol & - & $0.30 \mathrm{~g} / \mathrm{g}$ & [29] \\
\hline \multirow{2}{*}{$\begin{array}{l}\text { Clostridium beijerinckii } \\
\text { NRRL B-593 }\end{array}$} & \multirow[t]{2}{*}{ Raw glycerol } & \multirow{2}{*}{$\begin{array}{l}\text { Immobilized bioreactor } \\
\text { continuous operation }\end{array}$} & $0.78 \mathrm{~g} / \mathrm{g}$ (ceramic rings) & \multirow[t]{2}{*}{ [68] } \\
\hline & & & $0.79 \mathrm{~g} / \mathrm{g}$ (pumice stones) & \\
\hline \multicolumn{5}{|l|}{ 2,3-Butanediol } \\
\hline Paenibacilluspolymyxa & $\begin{array}{l}\text { Raw inulin extract from } \\
\text { Jerusalemartichoke tuber }\end{array}$ & Batch fermentation & $0.88 \mathrm{~g} / \mathrm{l} / \mathrm{h}$ & [23] \\
\hline \multicolumn{5}{|l|}{ 2,4-Pentanediol } \\
\hline Candida boidinii KK912 & 2,4-Pentanedione & - & - & {$[69]$} \\
\hline
\end{tabular}

"PUF: polyurethanefoam, a material packed in column bioreactors.

2,4-pentanedione and stereo-inversion of the isomeric mixture of 2,4-pentanediol [69].

The carbon chain of pentanediols is longer, which possibly has a negative effect on microbial production. For further development, utilization of pentose sugar like xylose or C5 intermediates of metabolic pathways like citrate and $\alpha$-ketoglutarate is likely to be a promising method. Zheng et al. realized microbial production of C5 monohydric alcohol, which provides an interesting perspective for $\mathrm{C} 5$ diols [71]. For example, through appropriate selection or manipulation P450 monooxygenase can be used for hydroxylating C5 monohydric alcohol to $\mathrm{C} 5$ diols.

\section{Metabolic pathway \\ 1,3-PDO}

The metabolic pathways of 1,3-PDO production are mainly concentrated on two routes. One pathway can produce 1,3-PDO from glycerol. The glycerol pathway involves two enzymes - glycerol dehydratase which catalyzes the dehydration of glycerol to 3-hydroxypropionaldehyde, and 1,3-PDO dehydrogenase which subsequently converts the 3-hydroxypropionaldehyde to 1,3-PDO. 1,3-PDO dehydrogenases are NADPH- or NADH-dependent, like DhaT from Klebsiella pneumoniae and YqhD from E. coli [72]. The other pathway is starting from monosaccharide or polysaccharide substrates, producing 1,3-PDO from glucose, corn hydrolysate or sugarcane molasses. No known natural organism ferments sugars directly to 1,3-PDO. The attempts using sugars as substrate have been made with either multistage fermentations involving a combination of microorganisms $[73,74]$ or genetically engineered microorganisms $[8,75]$ carrying genes for the conversion of sugar to glycerol and then to 1,3-PDO.

The corresponding reactions of 1,3-PDO production are summed up as below. $\mathrm{O}_{2}$ is required in glucose production route. This indicates that dissolved oxygen concentration will have great impact on the 1,3-PDO production. In glycerol route, growth occurs by the oxidative consumption of glycerol to produce cell mass concomitant with the accumulation of by-products (e.g. acetate) and the generation of excess NADH when oxygen is absent. The NADH cannot accumulate and must be converted to $\mathrm{NAD}^{+}$so as to maintain a steady-state 
Table 2 Engineered strains for diols production

\begin{tabular}{|c|c|c|c|c|c|}
\hline Strains & Genes/Enzymes & Substrate & Methods & Productivity/Yield & Reference \\
\hline \multicolumn{6}{|l|}{ 1,3-Propanediol } \\
\hline $\begin{array}{l}\text { Clostridium acetobutylicum } \\
\text { DG1(pSPD5) }\end{array}$ & $\begin{array}{l}\text { Glycerolkinase, Glycerol-3-phosphate } \\
\text { dehydrogenase }\end{array}$ & Glycerol & Continuous cultures & - & [65] \\
\hline Recombinant E. coli & $\begin{array}{l}\text { Glycerol3-phosphate dehydrogenase, } \\
\text { glycerol 3-phosphate phosphatase, } \\
\text { Insert dhaB1-3, yqhD, Delete tpi }\end{array}$ & Glucose & $\begin{array}{l}\text { Fed-batch } \\
\text { fermentation }\end{array}$ & $4 \mathrm{~g} / \mathrm{l} / \mathrm{h}$ & [8] \\
\hline \multicolumn{6}{|l|}{ 1,2-Propanediol } \\
\hline Escherichia coli & $\begin{array}{l}\text { Methylglyoxalsynthase, Glycerol } \\
\text { dehydrogenase, Aldehyde oxidoreductase, } \\
\text { ATP-dependentdihydroxyacetone kinase }\end{array}$ & Glycerol & Multi-fermentation & $0.21 \mathrm{~g} / \mathrm{g}$ & [41] \\
\hline $\begin{array}{l}\text { Saccharomyces cerevisiae } \\
\text { (sJDPMG) }\end{array}$ & Overexpress genes:gdh,GUPI, mgs, gldA & Glycerol & Flask cultivation & $0.21 \pm 0.02 \mathrm{~g} / \mathrm{g}$ & {$[45]$} \\
\hline $\begin{array}{l}\text { Synechococcus elongates } \\
\text { PCC } 7942\end{array}$ & $m g s A, y a h D, a d h$ & $\mathrm{CO}_{2}$ & Light condition & - & [26] \\
\hline Corynebacterium glutamicum & Overexpress genes:mgs, cgR_2242 & Glucose & Flask cultivation & $20 \mathrm{mg} / \mathrm{l} / \mathrm{h}$ & {$[38]$} \\
\hline Pichia pastoris & Introduce genes:mgsA, yghD, glydh & Glycerol & $\begin{array}{l}\text { Fed-batch } \\
\text { fermentation }\end{array}$ & $2 \mathrm{mg} / \mathrm{l} / \mathrm{h}$ & [70] \\
\hline \multicolumn{6}{|l|}{ 2,3-Butanediol } \\
\hline Serratiamarcescens $\mathrm{H} 303$ & swrW & Sucrose & Fed-batch culturing & $3 \mathrm{~g} / \mathrm{l} / \mathrm{h}$ & {$[56]$} \\
\hline Bacillus licheniformis & Knock out theldh & Glucose/Xylose & $\begin{array}{l}\text { Anaerobic } \\
\text { fermentation }\end{array}$ & $\begin{array}{l}0.45 \mathrm{~g} / \mathrm{g} \text { (BL5 glucose), } \\
0.44 \mathrm{~g} / \mathrm{g} \text { (BL8 xylose) }\end{array}$ & [51] \\
\hline \multirow[t]{2}{*}{ Escherichia coli SGSB03 } & \multirow[t]{2}{*}{ Introduce genes: budA, meso-budC } & \multirow[t]{2}{*}{ Glucose/Glycerol } & \multirow[t]{2}{*}{ Batch culture } & $0.31 \mathrm{~g} / \mathrm{g}$ (glucose) & \multirow[t]{2}{*}{ [15] } \\
\hline & & & & $0.21 \mathrm{~g} / \mathrm{g}$ (glycerol, $)$ & \\
\hline \multirow[t]{2}{*}{ Escherichia coli MGLAP } & $\begin{array}{l}\text { Acetoacetate synthase, } \\
\text { Acetoacetatedecarboxylase, }\end{array}$ & \multirow[t]{3}{*}{ Cellodextrin } & \multirow[t]{2}{*}{ Anaerobic cultivation } & $0.84 \mathrm{~g} / \mathrm{g}$ & \multirow[t]{2}{*}{ [19] } \\
\hline & Secondary alcohol dehydrogenase & & & & \\
\hline \multicolumn{5}{|l|}{ 1,4-Butanediol } & \\
\hline Escherichia coli & $\begin{array}{l}\text { Knock out genes: adhE, } \\
p f l B, I d h A \text {, Replace IpdA }\end{array}$ & & Fed-batchfermentation & $0.16 \mathrm{~g} / \mathrm{l} / \mathrm{h}$ & {$[58]$} \\
\hline
\end{tabular}

concentration of $\mathrm{NADH}$ and $\mathrm{NAD}^{+}$within the cell. Thus, $\mathrm{NAD}^{+}$is regenerated by the reductive conversion of glycerol to 1,3-propanediol in two steps as shown in Figure 2.

Glycerol:

$$
\mathrm{C}_{3} \mathrm{H}_{8} \mathrm{O}_{3} \rightarrow 0.875 \mathrm{C}_{3} \mathrm{H}_{8} \mathrm{O}_{2}+0.375 \mathrm{CO}_{2}+0.5 \mathrm{H}_{2} \mathrm{O}
$$

Max Yield: $0.72 \mathrm{~g} / \mathrm{g}$
Glucose:

$$
\begin{aligned}
& \mathrm{C}_{6} \mathrm{H}_{12} \mathrm{O}_{6}+0.18 \mathrm{O}_{2} \rightarrow 1.45 \mathrm{C}_{3} \mathrm{H}_{8} \mathrm{O}_{2}+1.64 \mathrm{CO}_{2} \\
& \quad+0.18 \mathrm{H}_{2} \mathrm{O}
\end{aligned}
$$

Max Yield: $0.61 \mathrm{~g} / \mathrm{g}$

The maximum theoretical yield of 1,3-PDO from

\begin{tabular}{|c|c|c|c|c|}
\hline Diols & $\begin{array}{l}\text { Boiling } \\
\text { point }\end{array}$ & Applications & Price $\$ /$ ton & Cost* \$/ton \\
\hline 1,3-propanediol & $210-211^{\circ} \mathrm{C}$ & a building block of polymers; antifreeze in wood paint. & $1500-1600$ & 774 \\
\hline 1,2-propanediol & $188.2^{\circ} \mathrm{C}$ & $\begin{array}{l}\text { unsaturated polyester resins; used in the oil dispersant; environmentally friendly } \\
\text { automotive antifreeze; }\end{array}$ & $900-1400$ & 774 \\
\hline 2,3-butanediol & $183-184^{\circ} \mathrm{C}$ & ingredients of methylethylketone; a precursor of chiral carriers of drug; a flavouring agent & $1000-5000$ & 1300 \\
\hline 1,4-butanediol & $228^{\circ} \mathrm{C}$ & elastic fibers and polyurethanes; a recreational drug; the synthesis of $\gamma$-butyrolacton & $2200-2500$ & - \\
\hline 1,3-butanediol & $207.5^{\circ} \mathrm{C}$ & a humectant and softener; a material for liquid crystals & $4000-5000$ & - \\
\hline
\end{tabular}
glycerol is clearly higher than that from glucose. It is

Table 3 Some main details about diols

${ }^{*}$ Cost represents the estimated price which is calculated according to the direct cost of the substrate (glucose). 


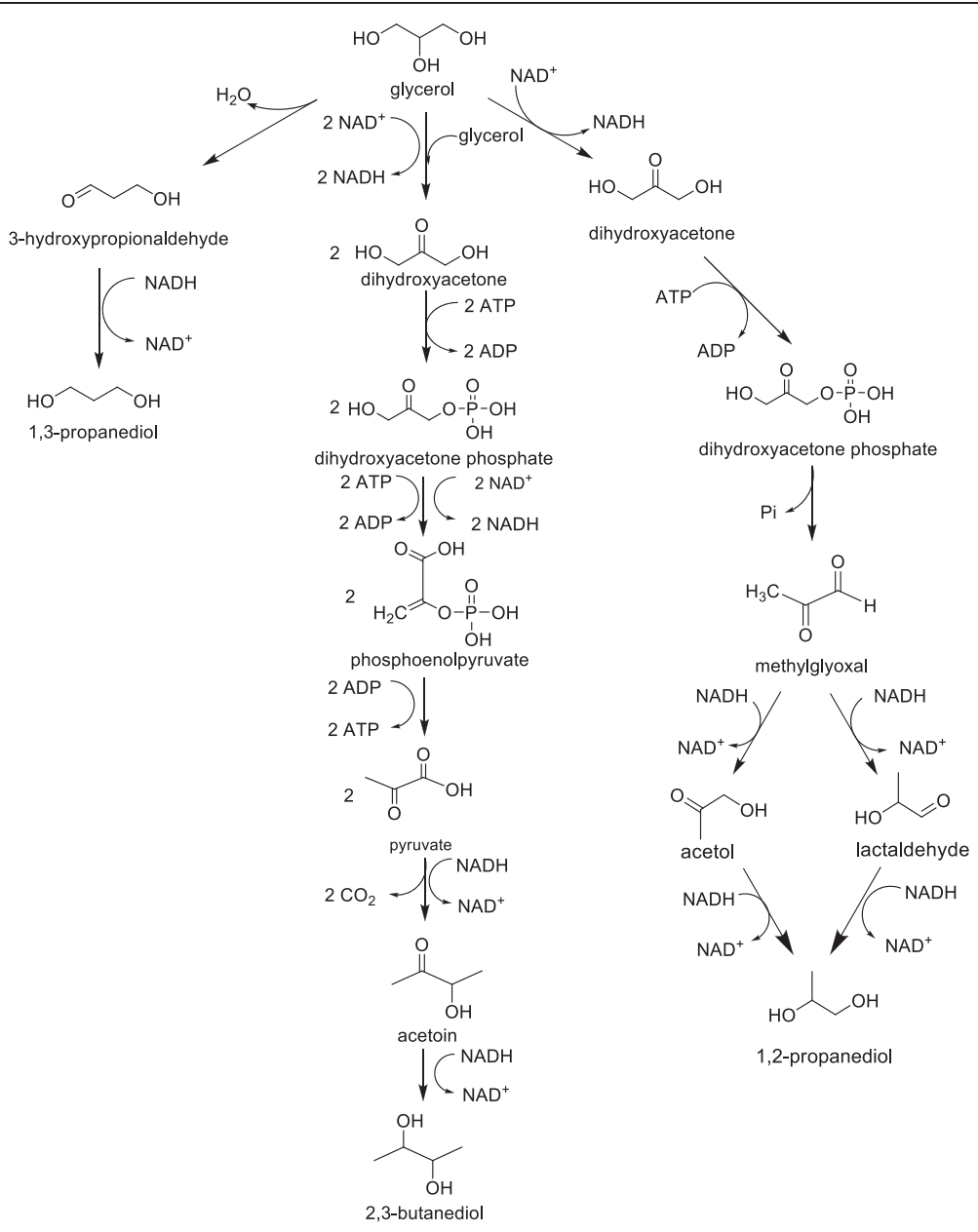

Figure 2 Glycerol metabolism pathways of 1,3-PDO, 1,2-PDO and 2,3-BDO production.

clear that glucose is more demanding in terms of stoichiometric requirements for balance. What's more, seeing from figures (Figures 2 and 3), the glucose pathway is indeed via glycerol, then to produce 1,3-PDO. Considering the cost, glycerol, a by-product of biodiesel, is a competitive substrate for 1,3-PDO production on account of its low cost, abundance, and the higher degree of reduction.

Though the oxygen is not needed in the glycerol reaction, low amounts of oxygen enable a better growth of the culture and therefore increase the overall number of biocatalysts for the conversion of glycerol to 1,3-PDO and thus increasing the 1,3-PDO production. Vitamin $\mathrm{B} 12$ is the co-factor of most glycerol dehydratases. It was reported that the level of 1,3-PDO production was improved when vitamin B12 was added to the culture medium [28]. So it is likely that an efficient synthesis of Vitamin B12 by the cell is helpful to maintain a high level of activity of glycerol dehydratase then to improve 1,3-PDO production.

\section{1,2-PDO}

In 1,2-PDO production, glucose is the most widely used sugar substrate [76-78]. Glucose undergoes glycolysis and enters the 1,2-PDO pathway by dihydroxyacetone phosphate (DHAP) which is metabolized to methylglyoxal (MG). From MG, two pathways, lactaldehyde-forming and acetol-forming pathway, are found to produce 1,2-PDO [70]. Owing to the wide availability, low-price, and high degree of reduction, glycerol is an attractive carbon source for the production of 1,2-PDO. In contrast to the 1,3PDO pathways that convert glycerol directly to diols in two-steps, the typical fermentative pathways for 1,2-PDO production from glycerol require the conversion of the carbon source to DHAP through glycolytic pathways, which requires that the organism of interest possesses the ability to utilize glycerol directly [79]. The glycerol pathway and glucose pathway are respectively summarized in Figures 2 and 3.

The best possible yield of 1,2-PDO is obtained from a simple stoichiometric balance without consideration of 


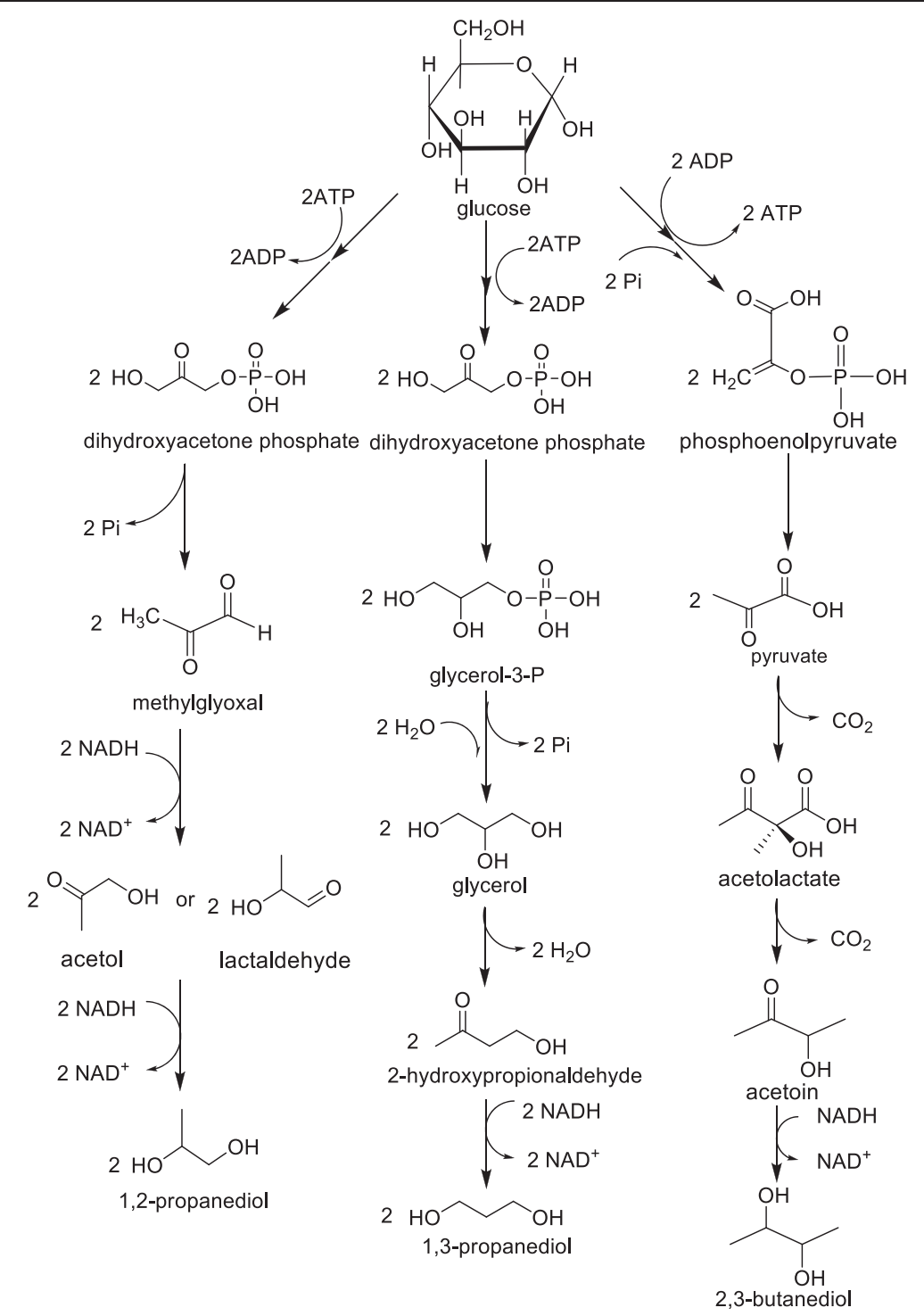

Figure 3 Glucose metabolism pathways of 1,3-PDO, 1,2-PDO and 2,3-BDO production.

metabolic pathways or energetics, for example, the yield from glucose is $0.84 \mathrm{~g} / \mathrm{g}$. In actual fermentation, more oxidized co-products must be produced to maintain an overall electron balance. Furthermore, sufficient energy in the form of ATP must be generated to enable the fermenting organisms to grow and remain viable. However, this yield obtained from a simple stoichiometric balance indicates that a high-yielding photochemical or electrochemical route to PDO may be possible in the future.

Considering the metabolic pathways and energetics, the corresponding reactions of 1,2-PDO production are summed up as below. Both routes need oxygen. Though the max yields of these two reactions are comparable, glycerol pathway (Figure 2) requires less NADH and ATP compared with glucose pathway (Figure 3). In addition, the glycerol pathway has fewer steps, thus this makes the metabolic engineering easy to operate on this pathway.

Glycerol:

$$
\begin{aligned}
& \mathrm{C}_{3} \mathrm{H}_{8} \mathrm{O}_{3}+0.23 \mathrm{O}_{2} \rightarrow 0.82 \mathrm{C}_{3} \mathrm{H}_{8} \mathrm{O}_{2}+0.56 \mathrm{CO}_{2} \\
& \quad+0.73 \mathrm{H}_{2} \mathrm{O}
\end{aligned}
$$

Max Yield: $0.67 \mathrm{~g} / \mathrm{g}$

Glucose:

$$
\begin{aligned}
& \mathrm{C}_{6} \mathrm{H}_{12} \mathrm{O}_{6}+0.18 \mathrm{O}_{2} \rightarrow 1.45 \mathrm{C}_{3} \mathrm{H}_{8} \mathrm{O}_{2}+1.64 \mathrm{CO}_{2} \\
& \quad+0.18 \mathrm{H}_{2} \mathrm{O}
\end{aligned}
$$

Max Yield: $0.61 \mathrm{~g} / \mathrm{g}$

There is still a gap between the actual yield and the theoretical one so that different cultivation parameters, 
such as oxygen supply, feeding-strategy, or medium composition are deserved to be applied in actual fermentation. Fed-batch fermentation and multi-fermentation is effective in product increase. The co-fermentation of glucose and glycerol in some organisms like Lactobacillus diolivorans leads to a shift from NADH-consuming to $\mathrm{NADH}$-producing reactions during glucose catabolism. This indicates a promising aspect in improvement to product yield.

\section{2,3-BDO}

The biosynthesis pathways of 2,3-BDO using glycerol and glucose as substrates are respectively shown in Figures 2 and 3. In glucose production route, respiratory quotient is an important variable. Under microaerobic conditions, oxygen competes for NADH consumption among the lactate pathway and the ethanol pathway, thus the formation of lactate and ethanol would reduce. Under conditions of adequate oxygen supply, the TCA cycle is also active, which competes for the intermediate pyruvate with the 2,3-BDO pathway and supplies additional energy (ATP) and reducing equivalents, leading to a decreased formation of 2,3-BDO. Glycerol has a lower energy value compared with glucose and other 6-carbon carbohydrates, therefore, compared to glucose, glycerol is expected to result in lower yields of pyruvatederived biochemical.

The corresponding reactions of 2,3-BDO production are summed up as below. The max yields of these two reactions are comparable. Glycerol pathway requires ATP, while glucose pathway produces ATP. Considering the energy consumption, glucose pathway is more advantageous.

Glycerol:

$$
\begin{aligned}
& \mathrm{C}_{3} \mathrm{H}_{8} \mathrm{O}_{3}+1.39 \mathrm{O}_{2} \rightarrow 0.47 \mathrm{C}_{4} \mathrm{H}_{10} \mathrm{O}_{2}+1.11 \mathrm{CO}_{2} \\
& \quad+1.63 \mathrm{H}_{2} \mathrm{O}
\end{aligned}
$$

Max Yield: 0.46 g/g

Glucose:

$$
\begin{aligned}
& \mathrm{C}_{6} \mathrm{H}_{12} \mathrm{O}_{6}+2 \mathrm{ADP}+\mathrm{NAD}^{+} \rightarrow \mathrm{C}_{4} \mathrm{H}_{10} \mathrm{O}_{2}+2 \mathrm{CO}_{2} \\
& +2 \mathrm{ATP}+2 \mathrm{H}_{2} \mathrm{O}+\mathrm{NADH}+\mathrm{H}^{+}
\end{aligned}
$$

\section{Max Yield: $0.5 \mathrm{~g} / \mathrm{g}$}

Compared with PDO productions, the utilization efficiency of carbon atom in 2,3-BDO production is obviously lower, no matter that the substrate is glycerol or glucose. The reason is the more release of $\mathrm{CO}_{2}$ in synthetic pathways, namely, the carbon loss. To improve efficiency, reuse of $\mathrm{CO}_{2}$ or carbon rearrangement avoiding the release of $\mathrm{CO}_{2}$ is likely to be an effective way [80].

\section{1,4-BDO}

1,4-BDO production pathways from glucose are shown in Figure 4. The non-naturally 1,4-BDO production was

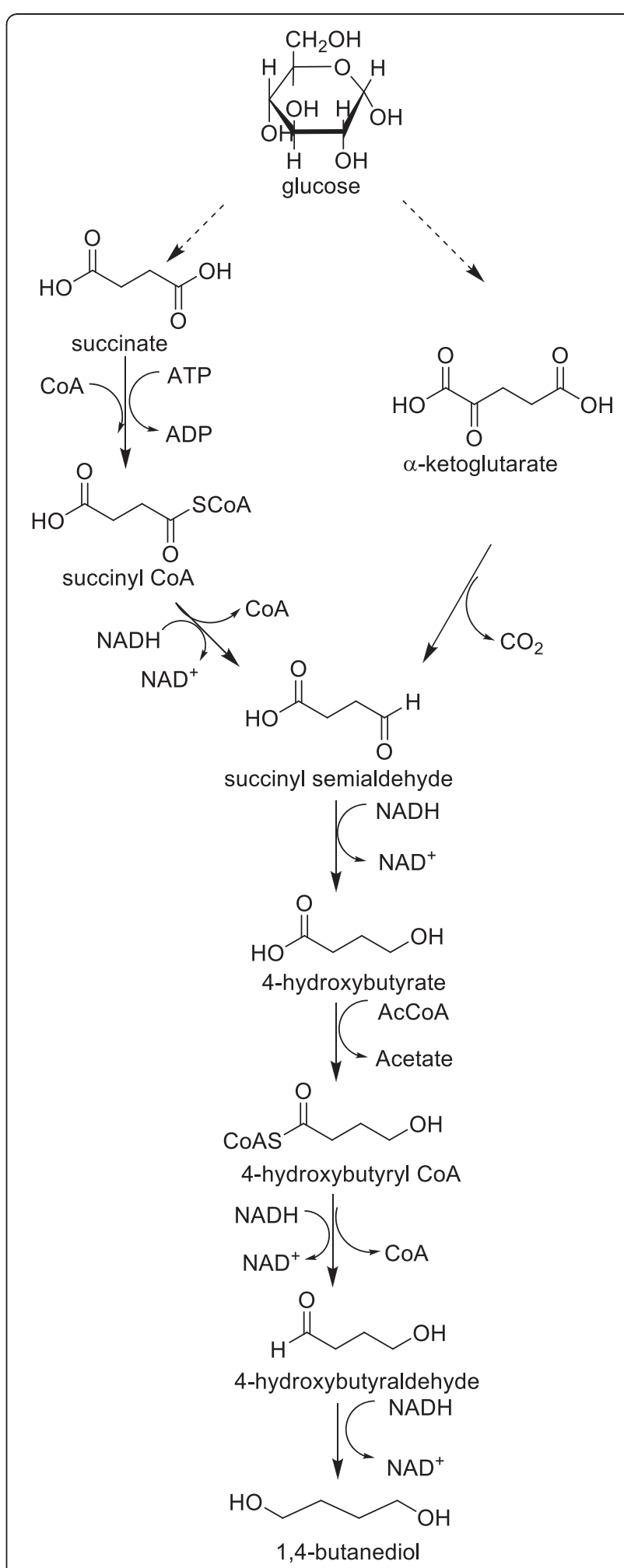

Figure 4 Glucose metabolism pathways of 1,4-BDO production. 
reported in patents [81-83]. In WO patent 2011047101, researchers demonstrated 1,4-BDO production pathways from succinate, succinyl-coenzyme A ( $\mathrm{CoA})$ and $\alpha$-ketoglutarate [83]. Another invention provided a nonnaturally occurring microbial biocatalyst to produce 1,4-BDO from 4-hydroxybutanoic acid with various pathways including the use of the native $E$. coli SucD enzyme to convert succinate to succinyl-CoA, and the use of $\alpha$-ketoglutarate decarboxylase in the $\alpha$-ketoglutarate pathway [81].

\section{Fermentation process}

On an industrial scale, the production costs can be decreased by increasing the process productivity as well as shortening the time for upstream and downstream processes. Immobilization techniques can help to reach the above goal. There are some studies with immobilized cell systems for PDO production. Clostridium beijerinckii was reported to produce 1,3-PDO using raw glycerol in immobilized cell system [68]. And yields were $0.78 \mathrm{~g} / \mathrm{g}$ and $0.79 \mathrm{~g} / \mathrm{g}$, respectively, when ceramic rings and pumice stones were used as immobilization supports. When using Klebsiella pneumoniae as producer for 1,3-PDO, ceramic-based cell immobilization achieved a higher production rate of $10 \mathrm{~g} / \mathrm{l} / \mathrm{h}$ in comparison with suspended cell system $4.9 \mathrm{~g} / \mathrm{l} / \mathrm{h}$. An immobilized Klebsiella sp. HE-2 cells were reported be used for six cycles without significant activity loss so as to greatly improve the operational stability and reusability of the cells [84].

Supporting material plays an important role in immobilization. Effective strain attachment to the packing material surface could improve the operational process. Gungormusler et al. revealed that ceramic materials were good candidates for immobilization purpose, and ceramic balls were better support materials than ceramic rings in terms of immobilization [85]. Zhao et al. investigated the potential of microcapsule of sodium cellulose sulfate/polydimethyl-diallyl-ammonium chloride (NaCS/PDMDAAC) in the immobilization of $K$. pneumoinae for 1,3-PDO production [86]. And a high 1,3-PDO productivity was up to $16.4 \mathrm{~g} / \mathrm{l} / \mathrm{h}$, however, they used pure glycerol as the substrate. Other researchers revealed the feasibility of using a novel microbial strain and packing material, namely, Pantoea agglomerans and Vukopor ${ }^{\circ} \mathrm{S} 10$, respectively, in the bioconversion of crude glycerol into 1,3-PDO in packed bed biofilm reactors [64]. When using polyurethanefoam as a packing stock, the productivity was $4 \mathrm{~g} / \mathrm{l} / \mathrm{h}$ much higher than $1 \mathrm{~g} / \mathrm{l} / \mathrm{h}$ in suspended cell systems. What's more, this strain demonstrated effective attachment to the packing material surface.

Most conventional fermentations are sterile processes. While the implement of non-sterile conditions minimizes the energy cost for sterilization, as well as the overall cost for equipment, various investigations were performed on non-sterile fermentation. 1,3-PDO fermentation can efficiently and successfully be performed under completely non-sterile fermentation conditions [87-89]. Microorganisms tested in these studies were strains of the species Clostridium butyricum and Klebsiella oxytoca. To find more species possessing this advantage, Citrobacter freundii was also cultured in non-sterilized fed-batch process, and 176 $\mathrm{g} / \mathrm{L}$ of raw glycerol were converted to $66 \mathrm{~g} / \mathrm{L}$ 1,3-PDO [27]. The absence of aseptic conditions proved to have no considerable effect on glycerol fermentation by $C$. freundii.

\section{Downstream recovery techniques}

Recovery and purification is a challenging aspect in the development of most fermentation processes, and is expected to also be the case for the short chain diols. For the cost effective biological production, a low energy required separation process with a high efficiency is essential. In recent years, a large amount of researches on 1,3-PDO, 1,2-PDO and 2,3-BDO separation have been reported. Because the properties of short chain dios are similar, existing recovery methods play a guiding role in researches. Figure 5 shows the main procedures and methods in diols separation.

\section{Traditional separation methods}

Many traditional separation methods involving distillation [47], pervaporation [90], steam stripping [91] and reverse osmosis [92] were established for the downstream processing. However, all these diols have boiling points that are significantly higher than that of water. For example, at $760 \mathrm{mmHg}$, the boiling points of 1,2-PDO and 1,3-PDO are 187.4 and $214^{\circ} \mathrm{C}$, respectively. Therefore, evaporation and distillation processes will require the removal of water from the PDO rather than the PDO from water.

Evaporation or vacuum distillation has been attempted for the recovery of 1,3-PDO but appeared unattractive and uneconomical $[93,94]$. Besides much energy consumption,

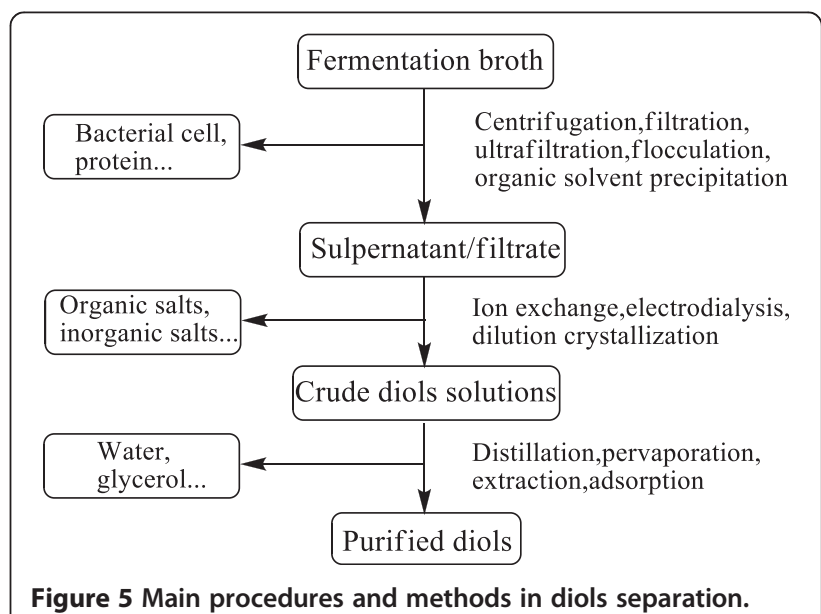


the broth required desalination before evaporation. And the desalination process of 1,3-PDO fermentation broth gave low product yields $[95,96]$. In order to save energy, multistage evaporation was ever investigated [97]. In single stage, the energy consumption was $1.2 \mathrm{~kg}$ steam $/ \mathrm{kg}$ evaporated, while it was only 0.5 in multi-stage evaporation.

Compared with the distillation, solvent extraction method has a series of advantages, such as high separation efficiency, great capacity of production, and low energy consumption, thus attracting much attention. But diols are strongly hydrophilic, and their densities are not sufficiently different from water, so standard liquid - liquid extraction couldn't achieve efficient separation. Various novel extraction methods are described in the following text.

\section{Complexation extraction}

The main processes of complexation extraction method are (i) solute in a solution for separation contacts with extractants which contain complexing agents (consisting of complexing agent, co-solvent, diluent), (ii) complexing agents react with the solute for separation forming complex, and (iii) the corresponding complex transfers to the extraction solvent phase to achieve separation [98,99].

Extractants are of great importance in complexation processes. The recovery of 1,2-PDO from aqueous solution was investigated using extractants consisting of ion pairs of Aliquat 336 and phenylboronate in 2-ethylhexanol, toluene, o-xylene, or di-isobutyl ketone and the separation scheme was based on the complexation of cis-vicinal diols with organoboronates [100]. Researchers recovered 1,3-PDO from dilute solution by complexation extraction using different complexing agents including tributyl phosphate, hexanoic acid, and octanoic acid [101].

Complexation extraction has advantages such as high selectivity and low cost. However, the distribution coefficients are not high so that this method is less efficiency. What's more, the choice of specific extractant and suitable recovery system should be taken into consideration for each diol. Hence, the develop of novel extractant system and the recovery of extractants deserves more investigations to improve economic efficiency and product yield.

\section{Reactive extraction}

In fermentation broth, the diols concentration is low. What's more, they are highly hydrophilic, so converting diols to hydrophobic chemicals and then extracting with an appropriate solution may be an effective separation way.

Reactive extraction is an easy and energy-efficient process. Studiers proposed a reactive extraction method for 1,3-PDO recovery using formaldehyde or acetaldehyde to block the hydroxyl groups and aromatic hydrocarbons to recover corresponding intermediates by solvent extraction [102]. A UNIFAC program was used to select an appropriate solvent for the extraction of dioxane (the product of 1,3-PDO acetalization) [103]. A reactive extraction process using various aldehydes (propionaldehyde, butylaldehyde and isobutylaldehyde) as both the reactants and the extractants was also proposed in a research [104].

Besides reactants and extractants, catalysts also have impact on the reactive extraction. Two types of ion exchange resins, Dowex and Amberlite, were investigated for the reactive extraction of 1,3-PDO and the overall conversion of 1,3-PDO was 98\% [105]. A low-cost sulfonated carbonbased catalyst was used for reactive extraction of 1,3-PDO from model fermentation mixture giving a conversion of 92\% with 0.7 g catalyst/ 1 g 1,3-PDO [106]. $\mathrm{ZrO}_{2}-\mathrm{MoO}_{3}$ solid heterogeneous catalyst was used in a reactive isolation approach for the recovery of 1,3-PDO from dilute aqueous solutions playing catalytic roles in both acetalization of 1,3-PDO and hydrolysis of 2-methyl-1,3-dioxane [107]. For $\mathrm{ZrO}_{2}-10$ wt $\% \mathrm{MoO}_{3}$, the conversion rate of 1,3-PDO in acetalization reached $96 \%$, and the acetals conversion in the hydrolysis reaction reached $97 \%$. Reactive-extraction has also been used to separate 2,3-BDO from fermentation broth using sulfuric acid or hydrochloric acid as the catalyst [92,108,109].

Reactive extraction is an easy and energy-efficient process in which the reaction takes place simultaneously with the extraction. The process requires a shorter operating time and a smaller amount of reactant and extractant. But the recovery of reactant and extractant is inevitable which may increase the operation cost. In the future, finding more suitable reactants or catalysts and improving the properties of catalysts may be the focuses of researches.

\section{Salting-out extraction}

Standard liquid-liquid extraction has been used to separate diols because of energy saving and simple process steps. However, the distribution coefficient of standard liquid-liquid extraction is not high in a dilute solution. Salting-out technology (the presence of inorganic salts decreasing aqueous solubility) was employed to overcome this obstacle. Salting-out extraction that employed a $\mathrm{K}_{2} \mathrm{HPO}_{4}$ /ethanol system consisting of $21 \%$ ethanol and $17 \% \mathrm{~K}_{2} \mathrm{HPO}_{4}$ (mass fraction) was investigated to separate 2,3-BDO from fermentation broth and 99\% of 2,3-BDO was recovered [110]. Some researchers studied the extraction of 2,3-BDO by adding different salts including $\mathrm{KAl}$ $\left(\mathrm{SO}_{4}\right)_{2},\left(\mathrm{NH}_{4}\right)_{2} \mathrm{SO}_{4}, \mathrm{~K}_{2} \mathrm{HPO}_{4}$, into solvent n-butanol. The results indicated that $\mathrm{K}_{2} \mathrm{HPO}_{4}$ was a promising salt with distribution coefficient of $5 \%$, separation factor of $43 \%$ and recovery yield of $80 \%$ [111].

Salting-out extraction is also employed to recovery of 1,3-PDO. One-salt and two-salt systems were used to separate 1,3-PDO [112]. The organic solvent selected was hydroxyl (pentanol, hexanol, tributyl phosphate, 2-propanol, 
and isopropanol) rather than aldehyde solvent. Other researchers performed a continuous extraction of 1,3-PDO in a packed column using dipotassium phosphate/ethanol as salting-out extraction system [113]. During an $11 \mathrm{~h}$ continuous operation, 1,3-PDO recovery of $90 \%$ was obtained for the real fermentation broth.

Salting-out extraction has an improved distribution coefficient but it requires the choice of an appropriate salt. Moreover, the addition of salts not only increases the cost but also causes equipment corrosions.

\section{In situ product extraction}

In situ product extraction during fermentation has been shown to be one of the advanced techniques that enhance the product recovery by reducing end-product effect.

A group of investigators tested the function of dealuminated $\mathrm{NaY}$ and Silicalite in separation of 1,3-PDO/aqueous solution. However, they didn't study the selectivity of the glycerol [114]. Other researchers tested different kinds of $\mathrm{X}$ zeolite, Y zeolite and a Na-ZSM-5 zeolite founding that Na-ZSM-5 was better than X zeolite and Y zeolite [115]. However, salts were possible to percolate into adsorbents reducing separation efficiency. What's more, the recovery of 1,3-PDO from the zeolite was not investigated.

Anvari and Khayati evaluated the feasibility of application of a series of selected solvents for the in situ extractive fermentation of $K$. pneumoniae in batch to overcome the accumulation effect of 2,3-BDO [116]. Results have clearly indicated that oleyl alcohol could be used as an alternative 2,3-BDO extractant. The effects of oleyl alcohol extraction on the 2,3-BDO formation by $K$. pneumonia were further investigated [117].

In situ product extraction reduces feedback inhibition; however, there are still some issues which need to be studied deeply, for example, the extraction efficiency of extractant, the reuse of extractant and the recovery of product from adsorbent.

\section{Aqueous two-phase extraction}

Aqueous two-phase extraction (ATPE) has advantages like mild extraction condition, high capacity and easy realization of industrialization enlargement. The widely used aqueous two-phase systems (ATPSs) for purification are based on polyethylene glycol/salt systems or polymer/polymer systems.

Recently, short-chain alcohol/inorganic salt systems are attracting more attention owing to their advantages such as low cost, easy recovery of alcohol and simple scale-up [118]. This system has been used to purify natural compounds $[119,120]$, as well as diol separation.

An ethanol/ammonium sulfate aqueous two-phase system (APTS) was investigated to separate 1,3-PDO from fermentation broth [121]. This method was easy to realize industrial scale, because it could achieve the simultaneous separation of microbial cells and 1,3-PDO simplifying the separation process. However, methanol was used in the recycling of ammonium sulfate, which should be separated with ethanol. This separation process caused additional energy demand and inevitable alcohol lost. Considering the above disadvantages, another ATPS composed of methanol/phosphate where methanol could be effectively used both as extractant (for 1,3-PDO) and solvent (for crystallizing the salt) was suggested and studied in detail [122]. This method resolved the problems of alcohol loss and high energy expenditure caused by separating the extractant and the solvent for crystallizing salt. Under conditions of $35 \%(\mathrm{v} / \mathrm{v})$ methanol, saturated concentration of phosphate and $\mathrm{pH} 10.7$, the recovery of 1,3-PDO was $98 \%$. Some researchers did a work to choose a suitable alcohol/salt ATPS and optimized with the response surface methodology [123].

The latest research progress on APTE is ionic liquidbased systems. Müller investigated the ability of water miscible ionic liquids to build ATPS for 1,3-PDO separation using 1-butyl-3-methylimidazolium trifluoromethansulfonate as the initial ionic liquid [124]. For an effective separation, there are some operational difficulties including the high phosphate concentration, waste stream requiring to be recycled and recovery of 1,3-PDO from the extract stream. An ionic liquid-based ATPS, phosphate/ 1-butyl-3-methylimidazolium trifluoromethanesulfonate $\left(\mathrm{Im}_{4,1} \mathrm{CF}_{3} \mathrm{SO}_{3}\right) /$ water, was investigated in detail including the effects of the temperature, $\mathrm{pH}$ and $\mathrm{Im}_{4,1} \mathrm{CF}_{3} \mathrm{SO}_{3}$, phosphate and 1,3-PDO mass fractions on the phase diagram and the influence of the fermentation by-products on the liquid-liquid equilibrium [125]. Successively, researchers performed a continuously operated process in pilot-scale using the above mentioned aqueous two-phase system [126]. The PDO recovery for all simulated PDO mass fractions was nearly at $100 \%$ when using eight stages. Even though the extraction could be successfully performed, there are subjects including the investment cost, required space, and operational cost to be considered.

2,3-BDO and 1,3-PDO are similar in some properties. Researches on 1,3-PDO aqueous two-phase extraction has guidance for 2,3-BDO. Optimization of process variables for the 2,3-BDO extractive in ATPS and the phase system composition was studied using response surface methodology $[127,128]$. A variety of APTSs were proposed including isopropanol/ammonium sulfate system [129], ethanol/phosphate system [130], and ethanol/ammonium sulfate system [131].

Aqueous two-phase extraction has advantages like mild extraction condition, high capacity and easy realization of industrialization enlargement. Additionally, ionic liquids have a variety of advantages including odorless, no pollution, non-flammable, separated from product easily, easy recovery and used repeatedly. Ionic liquid-based 
ATPE has a more competitive potential of economization and industrialization with its avoidance of serious problems including environment, health, safety, and equipment corrosion which are caused by the use of conventional organic solvents. Aqueous two-phase extraction is a promising method deserving more investigations in the future.

\section{Adsorption chromatography}

The purification of 1,3-PDO was performed by the chromatographic purification method using various resins including DEAE cellulose, Amberlite, Dowex Monosphere and silica as stationary phase [132]. The yield of 1,3-PDO achieved was $89 \%$ with silica resin as stationary phase and a mixture of chloroform and methanol as eluent in gradient chromatography. In addition, advantages like simple equipment, easy maintenance and regeneration of silica gel made this method more promising.

In a recent study, newly developed chemically modified silica gels was examined for the recovery of 1,3-PDO from fermentation broth [133]. Through chemical modification, the mechanical strength of silica gels was improved and did not shrink or swell in organic solvents or aqueous solutions.

This method makes use of relatively simple equipment and easy maintenance. But the capacity of chromatography is not large enough to achieve industrial production.

\section{Technology-integrated separation}

Integration of classical technologies and improvement or optimization of traditional technologies is an effective method to enhance separation efficiency. An integrated separation process of solvent extraction using 1-butanol as extracting solvent and pervaporation using polydimethylsiloxane membrane was used to recover 2,3-BDO from a synthetic fermentation broth [134]. In a later report, the ZSM-5-filled polydimethylsiloxane membrane was studied to separate 1-butanol/2,3-butanediol demonstrating good membrane selectivity and product purity [135]. Continuous efforts were made to study the process energy consumption in pervaporation and vacuum membrane distillation separation of 2,3-BDO [136].

An invention provided a 2,3-BDO production method that comprises anaerobic fermentation of a substrate containing $\mathrm{CO}_{2}$ to produce the compound and recovery of 2,3-BDO by a combination of ATPE and distillation after fermentation [137]. With several combined steps, the final concentration of the product was $98 \%$. An integrated separation process based on reactive-extraction and reactive-distillation was developed in recovering 2,3BDO from fermentation broth [138]. After a complete separation process, the yield of 2,3-BDO is more than $90 \%$ with purity over $99 \% . \mathrm{H}_{2} \mathrm{SO}_{4}$ and $\mathrm{HCl}$ were used as catalyst of the separation process. Considering the equipment corrosion, they should be neutralized after reactive-distillation.

There are less reports on 1,4-BDO separation compared with 2,3-BDO. A recent invention disclosed several processes of isolating 1,4-BDO from the fermentation broth [139]. One process included using disc stack centrifugation and ultrafiltration to remove solids obtaining a liquid fraction, removing salts from the liquid fraction by evaporative crystallization and ion exchange, and distilling 1,4-BDO. In another embodiment, the solids were removed by disc stack centrifugation and ultrafiltration, remove of salts from the liquid fraction was achieved by nanofiltration and ion exchange, the final step was evaporation of water and distillation of 1,4-BDO.

Even though some properties of short chain diols are similar, each diol has its speciality so that reasonable separation methods are chosen according to the desire product. Give an example in reactive extraction, properties of different diols determine the choice of reactants and extractants. To summarize, methods and technologies studied so far have their advantages and drawbacks. Among the methods described above, aqueous two-phase extraction deserves more attentions.

\section{Conclusions}

Bio-based production of short chain diols as platform chemicals is a promising method to substitute traditional petroleum production. For the glucose-based microbial production of diols, substrate costs make up much of the whole production costs. Raw glycerol from biodiesel production is a cheaper substrate and has been used for diols production. To further minimize substrate costs, farming and forestry residues like straw, Jerusalem artichoke tubers and wood hydrolysate deserve thoroughly investigation. The photosynthetic production of diols from $\mathrm{CO}_{2}$ using photosynthetic bacterium like cyanobacterium deserves attention in the future. In the area of microbial producers, beside engineering E.coli stains, Klebsiella sp. also is a suitable biocatalyst for an outstanding tolerance for high concentration glycerol, the ability to produce different diols and a high productivity (for example, a final 2,3-BDO yield close to $90 \%$ of theoretic value), but the pathogenicity should be overcome by engineering methods. In fermentation process, immobilization can result in a higher productivity and simplify recovery which shows the huge potential in commercial applications. Recovery of diols from fermentation broth is still an obstacle on commercial microbial production. In terms of yield and energy consumption, methods and technologies studied so far have their limitations or drawbacks. For further development, combination of classic separation techniques with other mew ones is essential. In conclusion, the integration of fermentation and downstream recovery help to fulfill cost efficient production process. 


\section{Abbreviations}

1,2-PDO: 1,2-propanediol; 1,3-PDO: 1,3-propanediol; 1,2-BDO: 1,2-butanediol; 2,3-BDO: 2,3-butanediol; 1,3-BDO: 1,3-butanediol; 1,4-BDO: 1,4-butanediol; DHAP: Dihydroxyacetone phosphate; MG: Methylglyoxal; CoA: Coenzyme A; ATPE: Aqueous two-phase extraction; APTSs: Aqueous two-phase systems; APTS: Aqueous two-phase system.

\section{Competing interests}

The authors declare that they have no competing interests.

\section{Authors' contributions}

MX and WL developed the idea for the study. YJ did the literature review and prepared the manuscript. WL and $\mathrm{HZ}$ polished the paper. TC contributed to figures. NT did some literature review. All the authors approved the final manuscript.

\section{Acknowledgments}

This research was financially supported by National Natural Science Foundation of China (21376255, 21202179, 21206185); Natural Science Foundation of Shandong Province (ZR2013EMZO02); Sci-Tech Development Project of Qingdao (12-4-1-45-nsh, 12-1-4-9-(3)-jch); Qingdao Institute of Bioenergy and Bioprocess Technology Director Innovation Foundation for Young Scientists.

\section{Author details}

${ }^{1}$ CAS Key Laboratory of Bio-based Materials, Qingdao Institute of Bioenergy and Bioprocess Technology, Chinese Academy of Sciences, No. 189 Songling Road, Qingdao 266101, China. ${ }^{2}$ University of Chinese Academy of Sciences, Beijing, China.

Received: 2 May 2014 Accepted: 14 November 2014

Published online: 10 December 2014

\section{References}

1. Haas $T$, Jaeger $B$, Weber $R$, Mitchell $S$, King C: New diol processes: 1,3-propanediol and 1,4-butanediol. App/ Catal A-Gen 2005, 280:83-88.

2. Cukalovic A, Stevens CV: Feasibility of production methods for succinic acid derivatives: a marriage of renewable resources and chemical technology. Biofuels Bioprod Biorefining 2008, 2:505-529.

3. Deckwer WD: Microbial conversion of glycerol to 1,3-propanediol. FEMS Microbiol Rev 1995, 16:143-149.

4. Bennett G, San KY: Microbial formation, biotechnological production and applications of 1,2-propanediol. Appl Microbiol Biotechnol 2001, 55:1-9.

5. Jang YS, Kim B, Shin JH, Choi YJ, Choi S, Song CW, Lee J, Park HG, Lee SY: Bio-based production of C2-C6 platform chemicals. Biotechnol Bioeng 2012, 109:2437-2459.

6. Willke T, Vorlop K: Biotransformation of glycerol into 1,3-propanediol. Eur J Lipid Sci Technol 2008, 110:831-840.

7. Zeng AP, Sabra W: Microbial production of diols as platform chemicals: recent progresses. Curr Opin Biotechnol 2011, 22:749-757.

8. Nakamura CE, Whited GM: Metabolic engineering for the microbial production of 1,3-propanediol. Curr Opin Biotechnol 2003, 14:454-459.

9. Yazdani SS, Gonzalez R: Anaerobic fermentation of glycerol: a path to economic viability for the biofuels industry. Curr Opin Biotechnol 2007, 18:213-219.

10. Khanal SK, Rasmussen M, Shrestha P, Van Leeuwen HJ, Visvanathan C, Liu H: Bioenergy and biofuel production from wastes/residues of emerging biofuel industries. Water Environ Res 2008, 80:1625-1647.

11. Rausch KD, Belyea RL: The future of coproducts from corn processing. Appl Biochem Biotechnol 2006, 128:47-86.

12. Metsoviti M, Paramithiotis S, Drosinos EH, Galiotou-Panayotou M, Nychas GJE, Zeng AP, Papanikolaou S: Screening of bacterial strains capable of converting biodiesel-derived raw glycerol into 1,3-propanediol, 2,3-butanediol and ethanol. Eng Life Sci 2012, 12:57-68.

13. Jensen TØ, Kvist T, Mikkelsen MJ, Westermann P: Production of 1,3-PDO and butanol by a mutant strain of Clostridium pasteurianum with increased tolerance towards crude glycerol. AMB Express 2012, 2:1-7.

14. Mampel J, Meurer G, Eck J: Production Method. 2009. WO Patent App. PCT/ EP2009/059,132
15. Lee S, Kim B, Park K, Um Y, Lee J: Synthesis of pure meso-2,3-butanediol from crude glycerol using an engineered metabolic pathway in Escherichia coli. Appl Biochem Biotechnol 2012, 166:1801-1813.

16. Yang $Y$, Zhang $Y$, Sun $Y$, He $L$, Jiang $Y$ : Study on production of 2,3-butanediol from straw paper pulp hydrolysate fermentation by Klebsiella pneumoniae. Renew Energ Resour 2010, 28:53-58.

17. Cheng KK, Liu Q, Zhang JA, Li JP, Xu JM, Wang GH: Improved 2,3-butanediol production from corncob acid hydrolysate by fed-batch fermentation using Klebsiella oxytoca. Process Biochem 2010, 45:613-616.

18. Jiang LQ, Fang Z, Guo F, Yang LB: Production of 2,3-butanediol from acid hydrolysates of Jatropha hulls with Klebsiella oxytoca. Bioresour Technol 2012, 107:405-410.

19. Shin HD, Yoon SH, Wu J, Rutter C, Kim SW, Chen RR: High-yield production of meso-2,3-butanediol from cellodextrin by engineered $E$. coli biocatalysts. Bioresour Technol 2012, 118:367-373.

20. Ge $X$, Zhang W: A shortcut to the production of high ethanol concentration from Jerusalem artichoke tubers. Food Technol Biotechnol 2005, 43:241.

21. Szambelan K, Nowak J, Czarnecki Z: Use of Zymomonas mobilis and Saccharomyces cerevisiae mixed with Kluyveromyces fragilis for improved ethanol production from Jerusalem artichoke tubers. Biotechnol Lett 2004, 26:845-848.

22. Celińska E, Grajek W: Biotechnological production of 2,3-butanediol-current state and prospects. Biotechnol Adv 2009, 27:715-725.

23. Gao J, Xu H, Li Q, Feng X, Li S: Optimization of medium for one-step fermentation of inulin extract from Jerusalem artichoke tubers using Paenibacillus polymyxa ZJ-9 to produce R, R-2,3-butanediol. Bioresour Technol 2010, 101:7076-7082.

24. Fages J, Mulard D, Rouquet JJ, Wilhelm JL: 2,3-Butanediol production from Jerusalem artichoke, Helianthus tuberosus, by Bacillus polymyxa ATCC 12321. Optimization of k a profile. Appl Microbiol Biotechnol 1986, 25:197-202.

25. Sun LH, Wang XD, Dai JY, Xiu ZL: Microbial production of 2,3-butanediol from Jerusalem artichoke tubers by Klebsiella pneumoniae. Appl Microbiol Biotechnol 2009, 82:847-852.

26. Li H, Liao JC: Engineering a cyanobacterium as the catalyst for the photosynthetic conversion of $\mathrm{CO}_{2}$ to 1,2-propanediol. Microb Cell Fact 2013, 12:4.

27. Metsoviti M, Zeng AP, Koutinas AA, Papanikolaou S: Enhanced 1,3-propanediol production by a newly isolated Citrobacter freundii strain cultivated on biodiesel-derived waste glycerol through sterile and non-sterile bioprocesses. J Biotechnol 2012, 163:408-418.

28. Ainala SK, Ashok S, Ko Y, Park S: Glycerol assimilation and production of 1,3-propanediol by Citrobacter amalonaticus Y19. Appl Microbiol Biotechnol 2013, 97:5001-5011.

29. Gungormusler M, Gonen C, Ozdemir G, Azbar N: 1,3-Propanediol production potential of Clostridium saccharobutylicum NRRLB-643. New Biotechnol 2010, 27:782-788.

30. Arasu MV, Kumar V, Ashok S, Song H, Rathnasingh C, Lee HJ, Seung D, Park S: Isolation and characterization of the new Klebsiella pneumoniae J2B strain showing improved growth characteristics with reduced lipopolysaccharide formation. Biotechnol Bioprocess Eng 2011, 16:1134-1143.

31. da Cunha MV, Foster MA: Sugar-glycerol cofermentations in lactobacilli: the fate of lactate. J Bacteriol 1992, 174:1013-1019.

32. Talarico TL, Axelsson LT, Novotny J, Fiuzat M, Dobrogosz WJ: Utilization of glycerol as a hydrogen acceptor by Lactobacillus reuteri: purification of 1,3-propanediol: NAD+ oxidoreductase. Appl Environ Microbiol 1990, 56:943-948

33. Pflügl S, Marx H, Mattanovich D, Sauer M: 1,3-Propanediol production from glycerol with Lactobacillus diolivorans. Bioresour Technol 2012, 119:133-140.

34. Khan NH, Kang TS, Grahame DA, Haakensen MC, Ratanapariyanuch K, Reaney MJ, Korber DR, Tanaka T: Isolation and characterization of novel 1,3-propanediol-producing Lactobacillus panis PM1 from bioethanol thin stillage. Appl Microbiol Biotechnol 2013, 97:417-428.

35. Altaras NE, Etzel MR, Cameron DC: Conversion of Sugars to 1,2Propanediol by Thermoanaerobacterium thermosaccharolyticum HG-8. Biotechnol Prog 2001, 17:52-56.

36. Cameron DC, Cooney CL: A Novel Fermentation: The Production of $\mathrm{R}$ (-)-1,2-Propanediol and Acetol by Clostridium thermosaccharolyticum. Nat Biotechnol 1986, 4:651-654.

37. Tran-Din K, Gottschalk G: Formation of D(-)-1,2-propanediol and D (-)-lactate from glucose by Clostridium sphenoides under phosphate limitation. Arch Microbiol 1985, 142:87-92. 
38. Niimi S, Suzuki N, Inui M, Yukawa H: Metabolic engineering of 1,2-propanediol pathways in Corynebacterium glutamicum. Appl Microbiol Biotechnol 2011, 90:1721-1729.

39. Altaras NE, Cameron DC: Metabolic engineering of a 1,2-propanediol pathway in Escherichia coli. Appl Environ Microbiol 1999, 65:1180-1185.

40. Altaras NE, Cameron DC: Enhanced production of (R)-1,2-Propanediol by Metabolically Engineered Escherichia coli. Biotechnology Prog 2000, 16:940-946.

41. Clomburg JM, Gonzalez R: Metabolic engineering of Escherichia coli for the production of 1,2-propanediol from glycerol. Biotechnol Bioeng 2011, 108:867-879.

42. Jeon E, Lee S, Kim D, Yoon H, Oh M, Park C, Lee J: Development of a Saccharomyces cerevisiae strain for the production of 1,2-propanediol by gene manipulation. Enzyme Microb Technol 2009, 45:42-47.

43. Jung J-Y, Choi E-S, Oh M-K: Enhanced production of 1,2-propanediol by tpi1 deletion in Saccharomyces cerevisiae. J Microbiol Biotechnol 2008, 18:1797-1802.

44. Lee W, DaSilva NA: Application of sequential integration for metabolic engineering of 1,2-propanediol production in yeast. Metab Eng 2006, 8:58-65.

45. Jung JY, Lee JW: Production of 1,2-propanediol from glycerol in Saccharomyces cerevisiae. J Bicrobiol Biotechnol 2011, 21:846-853.

46. Ma C, Wang A, Qin J, Li L, Ai X, Jiang T, Tang H, Xu P: Enhanced 2,3-butanediol production by Klebsiella pneumoniae SDM. Appl Bicrobiol Biotechnol 2009, 82:49-57.

47. Afschar A, Vaz Rossell C, Jonas R, Quesada Chanto A, Schaller K: Microbial production and downstream processing of 2,3-butanediol. J Biotechnol 1993, 27:317-329.

48. Hespell R: Fermentation of xylan, corn fiber, or sugars to acetoin and butanediol by Bacillus polymyxa strains. Curr Microbiol 1996, 32:291-296.

49. De Mas C, Jansen NB, Tsao GT: Production of optically active 2,3butanediol by Bacillus polymyxa. Biotechnol Bioeng 1988, 31:366-377.

50. Marwoto B, Nakashimada Y, Kakizono T, Nishio N: Enhancement of ( $R, R$-2,3-butanediol production from xylose by Paenibacillus polymyxa at elevated temperatures. Biotechnol Lett 2002, 24:109-114.

51. Wang $Q$, Chen T, Zhao X, Chamu J: Metabolic engineering of thermophilic Bacillus licheniformis for chiral pure D-2,3-butanediol production. Biotechnol Bioeng 2012, 109:1610-1621.

52. Saha B, Bothast R: Production of 2,3-butanediol by newly isolated Enterobacter cloacae. Appl Microbiol Biotechnol 1999, 52:321-326.

53. Gaspar P, Carvalho AL, Vinga S, Santos H, Neves AR: From physiology to systems metabolic engineering for the production of biochemicals by Lactic Acid Bacteria. Biotechnol Adv 2013, 31:764-788.

54. Paul B: Enhanced Pyruvate to 2,3-Butanediol Conversion in Lactic Acid Bacteria. 2010. WO 2,010,037,114.

55. Zhang L, Yang Y, Sun JA, Shen Y, Wei D, Zhu J, Chu J: Microbial production of 2,3-butanediol by a mutagenized strain of Serratia marcescens H30. Bioresour Technol 2010, 101:1961-1967.

56. Zhang L, Sun JA, Hao Y, Zhu J, Chu J, Wei D, Shen Y: Microbial production of 2,3-butanediol by a surfactant (serrawettin)-deficient mutant of Serratia marcescens H30. J Ind Microbiol Biotechnol 2010, 37:857-862.

57. Jiang $X$, Zhang $H$, Yang J, Liu M, Feng H, Liu X, Cao Y, Feng D, Xian M: Induction of gene expression in bacteria at optimal growth temperatures. Appl Microbiol Biotechnol 2013, 97:5423-5431.

58. Yim H, Haselbeck R, Niu W, Pujol-Baxley C, Burgard A, Boldt J, Khandurina J, Trawick JD, Osterhout RE, Stephen R: Metabolic engineering of Escherichia coli for direct production of 1,4-butanediol. Nat Chem Biol 2011, 7:445-452.

59. Szmidt-Middleton HL, Ouellet M, Adams PD, Keasling JD, Mukhopadhyay A Utilizing a highly responsive gene, yhjX, in E. coli based production of 1,4-Butanediol. Chem Eng Sci 2013, 103:68-73.

60. Burgard AP, Burk MJ, Osterhout RE, Pharkya P: Organisms for the Production of 1,3-Butanediol; 2010. US 20100330635A1.

61. Burgard AP, Burk MJ, Osterhout RE, Sun J, Pharkya P: Microorganisms for Producing 1,3-Butanediol and Methods Related Thereto; 2012. US 20120319113A1.

62. Baeza-Jiménez R, López-Martinez L, De la Cruz-Medina J, Espinosa-de-losMonteros J, Garcla-Galindo H: Effect of glucose on 1,3-propanediol production by Lactobacillus reuteri. Revista Mexicana de Ingeniería Química 2011, 10:39-46.

63. Wang $Y$, Teng $\mathrm{H}$, Xiu Z: Effect of aeration strategy on the metabolic flux of Klebsiella pneumoniae producing 1,3-propanediol in continuous cultures at different glycerol concentrations. J Ind Microbiol Biotechnol 2011, 38:705-715.

64. Casali S, Gungormusler M, Bertin L, Fava F, Azbar N: Development of a biofilm technology for the production of 1,3-propanediol (1,3-PDO) from crude glycerol. Biochem Eng J 2012, 64:84-90

65. González-Pajuelo M, Meynial-Salles I, Mendes F, Soucaille P, Vasconcelos I: Microbial conversion of glycerol to 1,3-propanediol: physiological comparison of a natural producer, Clostridium butyricum VPI 3266, and an engineered strain, Clostridium acetobutylicum DG1 (pSPD5). Appl Environ Microbiol 2006, 72:96-101.

66. Chatzifragkou A, Dietz D, Komaitis M, Zeng AP, Papanikolaou S: Effect of biodiesel-derived waste glycerol impurities on biomass and 1,3-propanediol production of Clostridium butyricum VPI 1718. Biotechnol Bioeng 2010, 107:76-84.

67. Papanikolaou S, Ruiz-Sanchez P, Pariset B, Blanchard F, Fick M: High production of 1,3-propanediol from industrial glycerol by a newly isolated Clostridium butyricum strain. J Biotechnol 2000, 77:191-208.

68. Gungormusler M, Gonen C, Azbar N: Continuous production of 1,3-propanediol using raw glycerol with immobilized Clostridium beijerinckii NRRL B-593 in comparison to suspended culture. Bioprocess Biosyst Eng 2011, 34:727-733.

69. Matsumura S, Kawai Y, Takahashi Y, Toshima K: Microbial production of (2R,4R)-2,4-pentanediol by enatioselective reduction of acetylacetone and stereoinversion of 2,4-pentanediol. Biotechnol Lett 1994, 16:485-490.

70. Barbier GG, Ladd JL, Campbell ER: Genetic modification of Pichia Pastoris for production of propylene glycol from glycerol. Int J Genet Eng 2011, 1:6-13.

71. Zheng Y, Liu Q, Li L, Qin W, Yang J, Zhang H, Jiang X, Cheng T, Liu W, Xu X: Metabolic engineering of Escherichia coli for high-specificity production of isoprenol and prenol as next generation of biofuels. Biotechnol Biofuels 2013, 6:57

72. Johnson E, Lin E: Klebsiella pneumoniae 1,3-propanediol: NAD+ oxidoreductase. J Bacterio/ 1987, 169:2050-2054

73. Hartlep M, Hussmann W, Prayitno N, Meynial-Salles I, Zeng AP: Study of two-stage processes for the microbial production of 1,3-propanediol from glucose. Appl Microbiol Biotechnol 2002, 60:60-66.

74. Mendes FS, González-Pajuelo M, Cordier H, François JM, Vasconcelos I: 1,3-Propanediol production in a two-step process fermentation from renewable feedstock. Appl Microbiol Biotechnol 2011, 92:519-527.

75. Tang $X$, Tan Y, Zhu H, Zhao K, Shen W: Microbial conversion of glycerol to 1,3-propanediol by an engineered strain of Escherichia coli. Appl Environ Microbiol 2009, 75:1628-1634.

76. Badía J, Ros J, Aguilar J: Fermentation mechanism of fucose and rhamnose in Salmonella typhimurium and Klebsiella pneumoniae. J Bacteriol 1985, 161:435-437.

77. Boronat A, Aguilar J: Rhamnose-induced propanediol oxidoreductase in Escherichia coli: purification, properties, and comparison with the fucoseinduced enzyme. J Bacteriol 1979, 140:320-326.

78. Forsberg CW, Donaldson L, Gibbins L: Metabolism of rhamnose and other sugars by strains of Clostridium acetobutylicum and other Clostridium species. Can J Microbiol 1987, 33:21-26.

79. Clomburg JM, Gonzalez R: Anaerobic fermentation of glycerol: A platform for renewable fuels and chemicals. Trends Biotechnol 2012, 31:20-28.

80. Bogorad IW, Lin TS, Liao JC: Synthetic non-oxidative glycolysis enables complete carbon conservation. Nature 2013, 502:693-697.

81. Burk M, Van Dien S, Burgard A, Niu W: Compositions and Methods for the Biosynthesis of 1,4-Butanediol and its Precursors; 2008. WO 2,008,115,840.

82. Burk M, Burgard A, Osterhout R, SUN J: Microorganisms for the Production of 1,4-butanediol; 2010. WO 2,010,030,711

83. Haselbeck R, Trawick J, Niu W, Burgard A: Microorganisms for the production of 1,4-butanediol, 4-hydroxybutanal, 4-hydroxybutyryl-coa, putrescine and related compounds, and methods related thereto; 2011. WO 2,011,047,101.

84. Wong CL, Huang CC, Chen WM, Chang JS: Converting crude glycerol to 1,3-propandiol using resting and immobilized Klebsiella sp. HE-2 cells. Biochem Eng J 2011, 58:177-183.

85. Gungormusler M, Gonen C, Azbar N: Use of ceramic-based cell immobilization to produce 1,3-propanediol from biodiesel-derived waste glycerol with Klebsiella pneumoniae. J Appl Microbiol 2011, 111:1138-1147.

86. Zhao YN, Chen G, Yao SJ: Microbial production of 1,3-propanediol from glycerol by encapsulated Klebsiella pneumoniae. Biochem Eng J 2006 32:93-99. 
87. Temudo MF, Poldermans R, Kleerebezem R, van Loosdrecht M: Glycerol fermentation by (open) mixed cultures: a chemostat study. Biotechnol Bioeng 2008, 100:1088-1098.

88. Chatzifragkou A, Papanikolaou S, Dietz D, Doulgeraki Al, Nychas G-JE, Zeng AP: Production of 1,3-propanediol by Clostridium butyricum growing on biodiesel-derived crude glycerol through a non-sterilized fermentation process. Appl Microbiol Biotechnol 2011, 91:101-112.

89. Metsoviti M, Paraskevaidi K, Koutinas A, Zeng AP, Papanikolaou S: Production of 1,3-propanediol, 2,3-butanediol and ethanol by a newly isolated Klebsiella oxytoca strain growing on biodiesel-derived glycerol based media. Process Biochem 2012, 47:1872-1882.

90. Qureshi N, Meagher M, Hutkins R: Recovery of 2,3-Butanediol by Vacuum Membrane Distillation*. Sep Sci Technol 1994, 29:1733-1748.

91. Garg S, Jain A: Fermentative production of 2,3-butanediol: a review. Bioresour Technol 1995, 51:103-109.

92. Xiu ZL, Zeng AP: Present state and perspective of downstream processing of biologically produced 1,3-propanediol and 2,3-butanediol. Appl Microbiol Biotechnol 2008, 78:917-926.

93. Ames TT: Process for the Isolation of 1,3-Propanediol from Fermentation Broth; 2002. US 6,361,983 B1.

94. Kelsey DR: Purification of 1,3-Propanediol; 1996. US 5,527,973.

95. Gong Y, Tang Y, Wang X, Yu L, Liu D: The possibility of the desalination of actual 1,3-propanediol fermentation broth by electrodialysis. Desalination 2004, 161:169-178.

96. Hao J, Liu D: Desalination of fermented broth containing 1,3-propanediol by Electrodialysis [J]. Chin J Process Eng 2005, 1:36-39.

97. Hermann B, Patel M: Today's and tomorrow's bio-based bulk chemicals from white biotechnology. Appl Biochem Biotechnol 2007, 136:361-388.

98. Bi $\mathrm{P}$, Dong $H, Y u H$, Chang L: A new technique for separation and purification of I-phenylalanine from fermentation liquid: flotation complexation extraction. Sep Purif Technol 2008, 63:487-491.

99. Black FJ, Bruland KW, Flegal AR: Competing ligand exchange-solid phase extraction method for the determination of the complexation of dissolved inorganic mercury (II) in natural waters. Anal Chim Acta 2007, 598:318-333.

100. Broekhuis RR, Lynn S, King CJ: Recovery of propylene glycol from dilute aqueous solutions by complexation with organoboronates in ion-pair extractants. Ind Eng Chem Res 1996, 35:1206-1214.

101. Xiang B, Chen S, Liu D: Extraction of 1,3-propanediol in dilute fermentation broth. J Tsinghua University (Sci Technol) 2001, 41:53-55.

102. Broekhuis RR, Lynn S, King CJ: Recovery of propylene glycol from dilute aqueous solutions via reversible reaction with aldehydes. Ind Eng Chem Res 1994, 33:3230-3237.

103. Malinowski JJ: Evaluation of liquid extraction potentials for downstream separation of 1,3-propanediol. Biotechnol Tech 1999, 13:127-130.

104. Hao J, Liu H, Liu D: Novel route of reactive extraction to recover 1,3-propanediol from a dilute aqueous solution. Ind Eng Chem Res 2005, 44:4380-4385.

105. Malinowski JJ: Reactive extraction for downstream separation of 1,3-propanediol. Biotechnol Prog 2000, 16:76-79.

106. Boonoun P, Laosiripojana N, Muangnapoh C, Jongsomjit B, Panpranot J, Mekasuwandumrong O, Shotipruk A: Application of sulfonated carbon-based catalyst for reactive extraction of 1,3-propanediol from model fermentation mixture. Ind Eng Chem Res 2010, 49:12352-12357.

107. Wu M, Li C, Zhang J, Miao C, Zheng Y, Sun Y: ZrO $-\mathrm{MoO}_{3}$ for the Acetalization of 1,3-Propanediol from Dilute Solutions. Ind Eng Chem Res 2012, 51:6304-6309

108. Hao J, Xu F, Liu H, Liu D: Downstream processing of 1,3-propanediol fermentation broth. J Chem Technol Biotechnol 2006, 81:102-108.

109. Li Y, Zhu J, Wu Y, Liu J: Reactive-extraction of 2,3-butanediol from fermentation broth by propionaldehyde: Equilibrium and kinetic study. Korean J Chem Eng 2013, 30:73-81.

110. Dai J, Zhang Y, Xiu Z: Salting-out Extraction of 2,3-Butanediol from Jerusalem artichoke-based Fermentation Broth. Chin J Chem Eng 2011, 19:682-686.

111. Wu YY, Chen K, Zhu JW, Wu B, Ji L, Shen YL: Enhanced extraction of 2,3-butanediol by medley solvent of salt and $n$-butanol from aqueous solution. Can J Chem Eng 2014, 92:511-514.

112. Wu HS, Wang YJ: Salting-out effect on recovery of 1,3-propanediol from fermentation broth. Ind Eng Chem Res 2012, 51:10930-10935.

113. Hongxin F, Yaqin S, Zhilong $X$ : Continuous countercurrent salting-out extraction of 1,3-propanediol from fermentation broth in a packed column. Process Biochem 2013, 48:1381-1386.
114. Günzel B, Berke CH, Ernst S, Weitkamp J, Deckwer WD: Adsorption von Diolen aus Fermentationsmedien an hydrophobe Zeolithe. Chem Ing Tech 1990, 62:748-750.

115. Schöllner R, Einicke WD, Unverricht S, Brettner E: Investigations of adsorptive separation of glycerol/propane-1,3-diol in aqueous solution on zeolites by liquid phase adsorption. J Prakt Chem 1994, 336:404-407.

116. Anvari M, Khayati G: In situ recovery of 2,3-butanediol from fermentation by liquid-liquid extraction. J Ind Microbiol Biotechnol 2009, 36:313-317.

117. Pahlavanzadeh $H$, Khayati $G$, Ghaemi Nasser VFE: Liquid-liquid extraction of 2,3-butanediol from fermentation broth. Iran J Chem Chem Eng 2012, 31:59-63.

118. Greve A, Kula MR: Cost structure and estimation for the recycling of salt in a protein extraction process. Bioprocess Eng 1991, 6:173-177.

119. Tianwei T, Qing H, Qiang L: Purification of glycyrrhizin from Glycyrrhiza uralensis Fisch with ethanol/phosphate aqueous two phase system. Biotechnol Lett 2002, 24:1417-1420.

120. Zhi W, Deng Q: Purification of salvianolic acid B from the crude extract of Salvia miltiorrhiza with hydrophilic organic/salt-containing aqueous two-phase system by counter-current chromatography. J Chromatogr A 2006, 1116:149-152.

121. Li Z, Jiang B, Zhang D, Xiu Z: Aqueous two-phase extraction of 1,3-propanediol from glycerol-based fermentation broths. Sep Purif Technol 2009, 66:472-478.

122. Li Z, Teng H, Xiu Z: Extraction of 1,3-propanediol from glycerol-based fermentation broths with methanol/phosphate aqueous two-phase system. Process Biochem 2011, 46:586-591.

123. Aydoğan Ö, Bayraktar E, Mehmetoğlu Ü, Kaeding T, Zeng AP: Selection and optimization of an aqueous two-phase system for the recovery of 1,3-propandiol from fermentation broth. Eng Life Sci 2010, 10:121-129.

124. Müller A, Górak A: Extraction of 1,3-propanediol from aqueous solutions using different ionic liquid-based aqueous two-phase systems. Sep Purif Technol 2012, 97:130-136.

125. Müller A, Schulz R, Wittmann J, Kaplanow I, Górak A: Investigation of a phosphate/1-butyl-3-methylimidazolium trifluoromethanesulfonate/ water system for the extraction of 1,3-propanediol from fermentation broth. RSC Adv 2013, 3:148-156.

126. Müller A, Lutze P, Górak A: Experimental and theoretical investigation of multistage extraction of 1,3-propanediol using the extraction system phosphate/1-butyl-3-methylimidazolium trifluoromethanesulfonate/ water. Biotechnol Prog 2013, 29:933-942.

127. Ghosh S, Swaminathan T: Optimization of process variables for the extractive fermentation of 2,3-butanediol by Klebsiella oxytoca in aqueous two-phase system using response surface methodology. Chem Biochem Eng Q 2003, 17:319-326.

128. Ghosh S, Swaminathan T: Optimization of the phase system composition of aqueous two-phase system for extraction of 2,3-butanediol by theoretical formulation and using response surface methodology. Chem Biochem Eng Q 2004, 18:263-272.

129. Sun LH, Jiang B, Xiu ZL: Aqueous two-phase extraction of 2,3-butanediol from fermentation broths by isopropanol/ammonium sulfate system. Biotechnol Lett 2009, 31:371-376.

130. Jiang B, Li ZG, Dai JY, Zhang DJ, Xiu ZL: Aqueous two-phase extraction of 2,3-butanediol from fermentation broths using an ethanol/phosphate system. Process Biochem 2009, 44:112-117.

131. Li Z, Teng H, Xiu Z: Aqueous two-phase extraction of 2,3-butanediol from fermentation broths using an ethanol/ammonium sulfate system. Process Biochem 2010, 45:731-737.

132. Anand P, Saxena RK, Marwah RG: A novel downstream process for 1,3-propanediol from glycerol-based fermentation. Appl Microbiol Biotechnol 2011, 90:1267-1276.

133. Barski P, Kowalczyk J, Lindstaedt A, Puzewicz-Barska J, Witt D: Evaluation of solid phase extraction for downstream separation of propane-1,3-diol and butan-1-ol from fermentation broth. Process Biochem 2012, 47:1005-1010

134. Shao P, Kumar A: Recovery of 2,3-butanediol from water by a solvent extraction and pervaporation separation scheme. J Membr Sci 2009, 329:160-168.

135. Shao P, Kumar A: Separation of 1-butanol/2,3-butanediol using ZSM-5 zeolite-filled polydimethylsiloxane membranes. J Membr Sci 2009, 339:143-150.

136. Shao $P$, Kumar A: Process energy efficiency in pervaporative and vacuum membrane distillation separation of 2,3-butanediol. Can J Chem Eng 2011, 89:1255-1265 
137. Simpson SD, Fleming SE, Havill AM, RTrevethick S: Process for producing chemicals using microbial fermentation of substrates comprising carbon monoxide; 2012. US Patent 2012/0045807A1.

138. Li Y, Wu Y, Zhu J, Liu J, Shen Y: Separating 2,3-Butanediol from

Fermentation Broth using n-Butylaldehyde. J Saudi Chem Soc 2013, http://dx.doi.org/10.1016/j.jscs.2013.02.005.

139. Clark W, Japs M, Burk M: Process of Separating Components of a Fermentation Broth; 2010. WO Patent 2,010,141,780.

doi:10.1186/s12934-014-0165-5

Cite this article as: Jiang et al:: Microbial production of short chain diols. Microbial Cell Factories 2014 13:165.

\section{Submit your next manuscript to BioMed Central} and take full advantage of:

- Convenient online submission

- Thorough peer review

- No space constraints or color figure charges

- Immediate publication on acceptance

- Inclusion in PubMed, CAS, Scopus and Google Scholar

- Research which is freely available for redistribution 